\title{
Ontogeny of the elemental composition and the biomechanics of radular teeth in the chiton Lepidochitona cinerea
}

Wencke Krings ( $\square$ wencke.krings@uni-hamburg.de)

Universität Hamburg: Universitat Hamburg https://orcid.org/0000-0003-2158-9806

JAN-OLE BRÜTT

Universität Hamburg: Universitat Hamburg

STANISLAV N. GORB

Christian Albrechts Universität zu Kiel: Christian-Albrechts-Universitat zu Kiel

\section{Research Article}

Keywords: elemental composition, nanoindentation, functional gradients, material properties, Mollusca, biomechanics, functional morphology, feeding

Posted Date: January 27th, 2022

DOI: https://doi.org/10.21203/rs.3.rs-1299698/v1

License: (c) (i) This work is licensed under a Creative Commons Attribution 4.0 International License. Read Full License 


\section{Abstract \\ Background}

The radula, a chitinous membrane with embedded teeth, is one important molluscan autapomorphy. In some taxa (Polyplacophora and Patellogastropoda) one tooth type (the dominant lateral tooth) was studied intensively in the last decades with regard to its mechanical properties, chemical, and structural composition, and the relationship between these parameters. As the dominant lateral tooth is probably one of the best studied biological materials, it is surprising, that data on chemistry and mechanical properties of the other tooth types, present on a chiton radula, is lacking.

\section{Results}

We provide data on the elemental distribution and mechanical properties (hardness and elasticity, i.e. Young's modulus) of all teeth from the Polyplacophora Lepidochitona cinerea (Linnaeus, 1767) [Chitonidae: Ischnochitonidae]. The ontogeny of elements, determined by energy-dispersive X-ray spectroscopy, and of the mechanical properties, detected by nanoindentation, was studied for every single tooth type. Additionally, we performed breaking stress experiments with teeth under dry and wet condition, highlighting the high influence of the water content on the mechanical behaviour of the radula. We thereby could determine the forces and stresses, teeth can resist, which was previously not studied in representatives of Polyplacophora. Overall, we were able to relate the mineral (iron, calcium) content, the mechanical parameters, breaking force, and stress for each tooth type. This led to a better understanding of the relationship between structure, material, and function in radular teeth. Further, we aimed at determining the role of calcium for the mechanical behaviour of the teeth: we decalcified radulae by ethylenediaminetetraacetic acid and afterwards performed elemental analyses, breaking stress experiments and determined the mechanical properties. Among other things, we detected that wet and decalcified radular teeth could resist highest forces, since teeth have a higher range of bending motion leading to a higher capability of teeth to gain mechanical support from the adjacent tooth row.

\section{Conclusion}

We present novel data on the chemistry, mechanical properties, and the mechanical behaviour of chiton teeth, which allows conclusions about tooth function. We could also relate the parameters mentioned, which contributes to our understanding on the origins of mechanical property gradients and the processes reducing structural failure in radular teeth.

\section{Background}

\section{The molluscan autapomorphy for feeding}

The food processing and gathering structure, the radula, is an important autapomorphy of the molluscan phylum. Its diversity in morphology and structural organization has probably enabled the establishment of distinct ecological niches, rendering the Mollusca the second largest taxa next to Insecta [1].

The radula together with (1) the underlain odontophoral cartilages, (2) the surrounding radular muscles, (3) the alary processus, and (4), in some taxa, the jaw forms the feeding apparatus. The radula itself is a fibrous and chitinous membrane with small, embedded teeth (alpha chitin matrix with associated proteins) arranged serially in transversal and longitudinal rows [2, 3]. It is continuously renewed by the secretion of new teeth and membrane in the posterior 'radular sack' or 'building zone' and becomes maturated in the 'mineralization zone' by overlain epithelia $[4,5,6,7,8,9,10,11,12,13]$. Only the anterior tooth rows ('working zone') are actually used for feeding and come into contact with the ingesta (food, minerals, feeding substrate, etc.).

\section{The diversity of organism-ingesta interfaces}

As the molluscan species are highly distinct, radular morphologies, including tooth shape, arrangement, quantity, mechanical properties, and chemical composition, are diverse as well. The morphological diversity in tooth arrangement and quantity led to the categorization of radulae into five to seven basic radular types (e.g. docogloss, toxogloss, taeniogloss, isodont, rhipidogloss).

The precise shape of teeth is often used as taxonomic character, but as an interface to the ingesta, it reflects trophic preferences as well [e.g. 14, 15].

To gain deep insight into trophic adaptations, mechanical properties (e.g. elasticity, hardness, and breaking stress), which have a high influence on the tooth's biomechanics, and the tooth's chemical composition were investigated as well $[16,17,18,19,20,21,22,23,24,25,26,27,28,29,30]$.

Shape together with mechanical properties can reflect functional specializations of distinct tooth types on each radula, e.g. some teeth are rather used for scratching, and others for food gathering, together forming a multifunctional radula [15, 30, 31, 32, 33, 34, 35]. In some taxa, some teeth do not interact with ingesta; here the involvement depends on the feeding substrate roughness or teeth contribute to foraging by e.g. reinforcing the membrane [36, 37, 38]. Thus, in general, forces and functional loads on teeth can vary, even within one single radula.

Many on the past studies relating chemical composition, mechanical properties, morphology, functional loads, and ecology focus on Polyplacophora and patelliform Gastropoda with docoglossan and rhipidoglossan radulae [e.g. 20, 39, 40,41]. The dominant lateral teeth of these taxa, used for loosening algae from rocky feeding substrates, were very well studied in the last decades due to their immense hardness and stiffness [for throughout reviews see 42, 43, 44]. These mechanical properties are based on substantial proportions of iron-based incorporations, which increase the cusps' wear-resistance [18, 21, 45, 46, 47, $48,49,50]$, and at least one non-iron element incorporated in teeth (e.g. silicon, calcium), probably serving as mechanical reinforcement [43]. 
However, many more species await deep investigations with regard to tooth mineralization and mechanical properties, as e.g. in Polyplacophora $~ 20$ of $~ 940$ species were examined so far. In addition, even in the well investigated taxa, usually the heavy mineralized dominant lateral tooth (termed here lateral tooth II) was studied, whereas for all other tooth types (centrals, lateral teeth I, and marginals) analyses on the chemical composition and mechanical properties are lacking.

\section{Aim of the study}

Here we provide data on the elemental distribution, analysed by energy-dispersive X-ray spectroscopy (EDX), and the mechanical properties hardness and elasticity (Young's modulus), determined by nanoindentation, of teeth from Lepidochitona cinerea (Linnaeus, 1767) [Polyplacophora: Chitonida:

Ischnochitonidae]. We studied the radular ontogeny, with regard to chemistry and mechanical parameters, not only in for the dominant lateral teeth, but for every tooth type, which was not done before. Additionally, we focused on the mechanical behaviour of teeth, when hitting against an obstacle, and their ability to resist structural failure. This was done by measuring the force needed to break teeth and calculating the breaking stress (breaking force divided by crosssectional area of the tooth), which is also new set of data for Polyplacophora. We were able to relate such parameters as (1) mineral (iron, calcium) content, (2) hardness, (3) elasticity, (4) breaking force and (5) breaking stress for every tooth type, leading to hypotheses on tooth function. Further, we aimed at determining the role of calcium for the mechanical behaviour of the teeth: for this purpose, we decalcified radulae by ethylenediaminetetraacetic acid (EDTA) and performed afterwards EDX analyses, nanoindentation, and breaking stress experiments. These results were compared to those obtained on the untreated (native) radulae.

\section{Results}

\section{Radular morphology}

The radula of Lepidochitona cinerea is docogloss with seven teeth per row: the central tooth (Ct) is median, flanked by one small lateral tooth (Lt I), one dominant lateral tooth (Lt II), and one marginal tooth (Mt) on each side (Figure 1a). The central tooth is small and slender with a small spoon-like cusp. The lateral tooth I is of rather similar shape as the central tooth but exceed it in size. The lateral tooth II is the largest and most prominent tooth on the radula, its cusps is of paw-like shape possessing three denticles. The marginal teeth are slender, their styli are of a roundish shape and their cusps have a spoon-like morphology.

\section{Colour}

Overall, the radula has a yellowish colour gradually shifting into orange from the radular sack to the working zone, while remaining somewhat transparent (Figure 3a). The most prominent colour change during maturation can be observed in the lateral teeth II. In the radular sack they are of a rather uniformly distributed white-yellow colour. Within three rows, starting in tooth row 8 , their cusps change colour from pale yellow to a deeper yellow. From row 10 on, cusps become red and turn black and no transparency is left after row 17. The shift in colour from the black cusps to the yellow colour of the stylus in abrupt and not gradual (Figures 1g, 2a, 3a). This area had been termed previously as junction zone [see e.g. 51, 52].

The iron dominated lateral II tooth cusps of the treated specimens are similar in colour to the native ones; however, the styli and bases of the lateral teeth II as well as the centrals, lateral teeth I, marginals are rather whitish (Figures $1 \mathrm{~h}, 2 \mathrm{~b}, 4 \mathrm{a}$ ).

\section{Differences between individuals}

\section{Elemental proportions}

In all radulae of Lepidochitona cinerea (native and treated) we detect $\mathrm{Na}, \mathrm{K}, \mathrm{Si}, \mathrm{Mg}, \mathrm{P}, \mathrm{S}, \mathrm{Cl}, \mathrm{Ca}$, and Fe. These elements were found in all three zones of each individual. Data on proportions of each element in each radula are non-normally distributed. Kruskal-Wallis test detected no significant difference for the proportions of each individual element between individual radulae of either native or treated group, except for Si in native group (see Table 1). 
Table 1

For each individual whole radula. Mean, standard deviation (Sd), and quantity ( $n$ ) of analysed tooth areas (by EDX and nanoindentation) or quantity of broken teeth (by breaking stress experiments) for the following parameters are given: (a) proportions, given in \%, of $\mathrm{Na}, \mathrm{Mg}, \mathrm{Si}, \mathrm{P}, \mathrm{S}, \mathrm{Cl}, \mathrm{K}, \mathrm{Ca}$, $\mathrm{Fe}$, and all elements. Differences between the individual radulae for each condition (native or treated) were tested by Kruskal-Wallis test (orange $\mathrm{p}$-values = highly significant). (b) Young's modulus (E) and hardness $(\mathrm{H})$, given in GPa. Differences between the individual radulae for each condition (native or treated) were tested by ANOVA (red p-values = significant). (c) Breaking force (Bf), given in $\mathrm{mN}$, and breaking stress (Bs), given in MPa. Differences between the individual radulae for each condition (native dry, native wet, treated dry, or treated wet) were tested by t test (black p-values = not significant).

\begin{tabular}{|c|c|c|c|c|c|c|c|c|c|c|c|c|c|}
\hline \multirow[t]{2}{*}{ Parameter } & \multirow[t]{2}{*}{ Condition } & \multicolumn{3}{|c|}{ Individual 1} & \multicolumn{3}{|c|}{ Individual 2} & \multicolumn{3}{|c|}{ Individual 3} & \multicolumn{3}{|c|}{ Results from Kruskal-Wallis } \\
\hline & & Mean & Sd & $n$ & Mean & Sd & $n$ & Mean & Sd & $n$ & ChiSquare & df & p-value \\
\hline $\mathrm{Na}$ & Native & 0.03 & 0.23 & 687 & 0.04 & 0.29 & 695 & 0.03 & 0.22 & 692 & 0.5871 & 2 & 0.7456 \\
\hline $\mathrm{Mg}$ & Native & 0.02 & 0.14 & 687 & 0.02 & 0.15 & 695 & 0.02 & 0.15 & 692 & 0.9639 & 2 & 0.6176 \\
\hline $\mathrm{Si}$ & Native & 0.00 & 0.01 & 687 & 0.00 & 0.01 & 695 & 0.00 & 0.00 & 692 & 9.5023 & 2 & $0.0086^{\star}$ \\
\hline$P$ & Native & 0.09 & 0.47 & 687 & 0.07 & 0.44 & 695 & 0.09 & 0.09 & 692 & 1.1567 & 2 & 0.5608 \\
\hline S & Native & 0.02 & 0.08 & 687 & 0.02 & 0.08 & 695 & 0.02 & 0.08 & 692 & 0.0997 & 2 & 0.9514 \\
\hline $\mathrm{Cl}$ & Native & 0.01 & 0.05 & 687 & 0.00 & 0.02 & 695 & 0.00 & 0.03 & 692 & 0.6350 & 2 & 0.7280 \\
\hline K & Native & 0.00 & 0.02 & 687 & 0.00 & 0.02 & 695 & 0.00 & 0.05 & 692 & 4.3273 & 2 & 0.1149 \\
\hline $\mathrm{Ca}$ & Native & 1.55 & 2.33 & 687 & 1.53 & 2.40 & 695 & 1.51 & 2.39 & 692 & 0.1154 & 2 & 0.9439 \\
\hline $\mathrm{Fe}$ & Native & 1.99 & 5.86 & 687 & 1.94 & 5.77 & 695 & 1.95 & 5.85 & 692 & 0.2894 & 2 & 0.8653 \\
\hline All elements & Native & 3.69 & 7.93 & 687 & 3.63 & 7.95 & 695 & 3.62 & 7.91 & 692 & 0.0692 & 2 & 0.9660 \\
\hline $\mathrm{Na}$ & Treated & 0.00 & 0.03 & 684 & 0.00 & 0.00 & 694 & 0.00 & 0.00 & 690 & 1.0093 & 2 & 0.6037 \\
\hline $\mathrm{Mg}$ & Treated & 0.00 & 0.04 & 684 & 0.00 & 0.00 & 694 & 0.00 & 0.01 & 690 & 1.0093 & 2 & 0.6037 \\
\hline $\mathrm{Si}$ & Treated & 0.00 & 0.00 & 684 & 0.00 & 0.00 & 694 & 0.00 & 0.00 & 690 & 1.9827 & 2 & 0.3711 \\
\hline$P$ & Treated & 0.00 & 0.04 & 684 & 0.00 & 0.00 & 694 & 0.00 & 0.00 & 690 & 4.0546 & 2 & 0.1317 \\
\hline S & Treated & 0.00 & 0.01 & 684 & 0.00 & 0.00 & 694 & 0.00 & 0.01 & 690 & 4.7708 & 2 & 0.0921 \\
\hline $\mathrm{Cl}$ & Treated & 0.00 & 0.01 & 684 & 0.00 & 0.01 & 694 & 0.00 & 0.02 & 690 & 0.4275 & 2 & 0.8076 \\
\hline K & Treated & 0.00 & 0.01 & 684 & 0.00 & 0.02 & 694 & 0.00 & 0.01 & 690 & 0.6411 & 2 & 0.7258 \\
\hline $\mathrm{Ca}$ & Treated & 0.05 & 0.22 & 684 & 0.05 & 0.22 & 694 & 0.06 & 0.25 & 690 & 0.5467 & 2 & 0.7608 \\
\hline $\mathrm{Fe}$ & Treated & 2.13 & 6.17 & 684 & 2.17 & 6.25 & 694 & 2.20 & 6.39 & 690 & 0.5042 & 2 & 0.7772 \\
\hline \multirow[t]{3}{*}{ All elements } & Treated & 2.18 & 6.20 & 684 & 2.23 & 6.27 & 694 & 2.26 & 6.42 & 690 & 0.8869 & 2 & 0.6418 \\
\hline & & & & & & & & & & & \multicolumn{3}{|c|}{ Results from ANOVA } \\
\hline & & & & & & & & & & & F Ratio & $\mathrm{df}$ & $\mathrm{p}$-value \\
\hline $\mathrm{H}$ & Native & 1.41 & 0.96 & 687 & 1.48 & 0.98 & 695 & 1.33 & 0.90 & 692 & 4.5207 & 2 & $0.0110^{*}$ \\
\hline $\mathrm{E}$ & Native & 11.20 & 7.49 & 687 & 11.72 & 7.59 & 695 & 10.52 & 6.96 & 692 & 4.6125 & 2 & $0.0100 *$ \\
\hline $\mathrm{H}$ & Treated & 1.05 & 0.80 & 684 & 1.11 & 0.83 & 694 & 1.00 & 0.77 & 690 & 3.5028 & 2 & $0.0303^{\star}$ \\
\hline \multirow[t]{3}{*}{$E$} & Treated & 7.80 & 5.99 & 684 & 8.14 & 6.17 & 694 & 7.46 & 5.73 & 690 & 2.2726 & 2 & 0.1033 \\
\hline & & \multicolumn{3}{|c|}{ Individual 4} & \multicolumn{3}{|c|}{ Individual 5} & & & & \multicolumn{3}{|c|}{ Results from $t$ test } \\
\hline & & Mean & $\mathrm{Sd}$ & $n$ & Mean & $\mathrm{Sd}$ & $n$ & & & & t ratio & $\mathrm{df}$ & $\mathrm{p}$-value \\
\hline $\mathrm{Bf}$ & Native dry & 174.51 & 207.49 & 223 & 160.68 & 196.00 & 224 & & & & -0.72472 & 443.3292 & 0.7655 \\
\hline $\mathrm{Bf}$ & Native wet & 467.09 & 411.37 & 115 & 436.53 & 385.06 & 106 & & & & -0.5705 & 218.9456 & 0.7155 \\
\hline Bs & Native dry & 277.64 & 116.07 & 112 & 240.35 & 110.21 & 120 & & & & -2.50584 & 226.6855 & 0.9935 \\
\hline Bs & Native wet & 948.32 & 601.83 & 79 & 753.84 & 422.26 & 76 & & & & -2.33601 & 140.0989 & 0.9895 \\
\hline $\mathrm{Bf}$ & Treated dry & 116.20 & 143.46 & 216 & 79.84 & 75.68 & 217 & & & & -3.29606 & 325.7227 & 0.9995 \\
\hline $\mathrm{Bf}$ & Treated wet & 598.14 & 532.97 & 103 & 564.10 & 497.93 & 97 & & & & -0.46696 & 197.9883 & 0.6795 \\
\hline Bs & Treated dry & 617.32 & 284.14 & 108 & 399.47 & 221.08 & 116 & & & & -6.37196 & 201.9238 & 1.0000 \\
\hline Bs & Treated wet & 1387.87 & 735.62 & 78 & 1392.48 & 717.84 & 75 & & & & 0.039224 & 150.966 & 0.4844 \\
\hline
\end{tabular}


In all individual radulae of Lepidochitona cinerea (native and treated), the data on $\mathrm{E}$ and $\mathrm{H}$ are normally distributed. ANOVA detected significant differences between the individuals of the native group for $\mathrm{E}$ and $\mathrm{H}$ and between the individuals of the treated group for $\mathrm{H}$ (see Table 1).

\section{Breaking force and stress}

Breaking force and stress of each individual radula are normally distributed. T test detected no significant differences for both parameters between the individuals of the following groups: native dry, native wet, treated dry, treated wet (see Table 1).

\section{Whole radulae}

\section{Elemental proportions}

Proportions of all elements together are non-normal distributed in treated and native group. Native radulae possess more elements and Wilcoxon test detected significant difference for proportions of all elements between treated and native radulae (see Table 2).

Table 2

For each condition. Mean, standard deviation (Sd), and quantity ( $n$ ) of analysed tooth areas (by EDX and nanoindentation) or quantity of broken teeth (by breaking stress experiments) for the following parameters are given: (a) proportions, given in \%, of $\mathrm{Na}, \mathrm{Mg}, \mathrm{Si}, \mathrm{P}, \mathrm{S}, \mathrm{Cl}, \mathrm{K}$ $\mathrm{Ca}$, Fe, and all elements. Differences between the individual radulae for each condition (native or treated) were tested by Kruskal-Wallis test (orange $p$-values = highly significant, red = significant). (b) Young's modulus (E) and hardness $(\mathrm{H})$, given in GPa. Differences between the individual radulae for each condition (native or treated) were tested by Wilcoxon test (orange p-values = highly significant). (c) Breaking force (Bf), given in $\mathrm{mN}$, and breaking stress (Bs), given in MPa. Differences between the conditions (native, treated, native dry, native wet, treated dry, or treated wet) were tested by $t$ test or ANOVA (orange p-values = highly significant).

\begin{tabular}{|c|c|c|c|c|c|c|c|}
\hline \multirow[t]{2}{*}{ Parameter } & \multicolumn{4}{|l|}{ Mean \pm Sd } & \multicolumn{3}{|c|}{ Wilcoxon test } \\
\hline & \multicolumn{2}{|l|}{ Native } & \multicolumn{2}{|l|}{ Treated } & \multirow{2}{*}{$\begin{array}{l}\text { ChiSquare } \\
259.6057\end{array}$} & \multirow{2}{*}{$\begin{array}{l}\text { df } \\
1\end{array}$} & \multirow{2}{*}{$\begin{array}{l}\text { p-value } \\
<0.0001\end{array}$} \\
\hline All elements & $3.65 \pm 7.93$ & & $2.22 \pm 6.29$ & & & & \\
\hline $\mathrm{Fe}$ & $1.96 \pm 5.82$ & & $2.16 \pm 6.26$ & & 0.0101 & 1 & 0.9198 \\
\hline $\mathrm{K}$ & $0.02 \pm 0.03$ & & $0.00 \pm 0.01$ & & 3.0432 & 1 & 0.0811 \\
\hline $\mathrm{Na}$ & $0.03 \pm 0.25$ & & $0.00 \pm 0.02$ & & 46.9454 & 1 & $<0.0001$ \\
\hline $\mathrm{Mg}$ & $0.02 \pm 0.14$ & & $0.00 \pm 0.02$ & & 70.4860 & 1 & $<0.0001$ \\
\hline Si & $0.00 \pm 0.01$ & & $0.00 \pm 0.00$ & & 13.2788 & 1 & $<0.0003$ \\
\hline$P$ & $0.08 \pm 0.46$ & & $0.00 \pm 0.02$ & & 94.4597 & 1 & $<0.0001$ \\
\hline S & $0.02 \pm 0.08$ & & $0.00 \pm 0.01$ & & 168.1426 & 1 & $<0.0001$ \\
\hline $\mathrm{Cl}$ & $0.00 \pm 0.03$ & & $0.00 \pm 0.01$ & & 19.2699 & 1 & $<0.0001$ \\
\hline $\mathrm{Ca}$ & $1.53 \pm 2.37$ & & $0.05 \pm 0.23$ & & 938.3499 & 1 & $<0.0001$ \\
\hline $\mathrm{H}$ & $1.40 \pm 0.95$ & & $1.05 \pm 0.80$ & & 176.583 & 1 & $<0.0001$ \\
\hline \multirow[t]{3}{*}{ E } & $11.15 \pm 7.36$ & & $7.80 \pm 5.9$ & & 254.9487 & 1 & $<0.0001$ \\
\hline & & & & & \multicolumn{3}{|l|}{$\mathrm{T}$ test } \\
\hline & Dry & & Wet & & $\mathrm{t}$ & df & p-value \\
\hline \multirow[t]{2}{*}{ Breaking force } & $133.33 \pm 168.70$ & & $513.81 \pm 461.61$ & & 16.39621 & 474.4609 & $<0.0001$ \\
\hline & $n=880$ & & $n=421$ & & & & \\
\hline \multirow[t]{4}{*}{ Breaking stress } & $379.27 \pm 242.88$ & & $1119.80 \pm 687.50$ & & 18.15392 & 359.2179 & $<0.0001$ \\
\hline & $n=456$ & & $n=308$ & & & & \\
\hline & & & & & ANOVA & & \\
\hline & Native dry & Treated dry & Native wet & Treated wet & $\mathrm{F}$ & df & p-value \\
\hline \multirow[t]{2}{*}{ Breaking force } & $167.58 \pm 201.70$ & $97.98 \pm 115.92$ & $452.43 \pm 398.35$ & $581.63 \pm 515.26$ & 170.4726 & 3 & $<0.0001$ \\
\hline & $n=447$ & $n=433$ & $n=221$ & $n=200$ & & & \\
\hline \multirow[t]{2}{*}{ Breaking stress } & $258.35 \pm 114.36$ & $504.51 \pm 275.40$ & $852.96 \pm 528.96$ & $1390.13 \pm 724.56$ & 230.4705 & 3 & $<0.0001$ \\
\hline & $n=232$ & $n=224$ & $n=155$ & $n=153$ & & & \\
\hline
\end{tabular}

For the native radulae we determined that Fe occurs in the highest proportion, followed by $\mathrm{Ca}, \mathrm{P}, \mathrm{Na}, \mathrm{Mg}, \mathrm{S}, \mathrm{Cl}, \mathrm{K}$, and finally Si (see Table 2). In the treated radulae $\mathrm{Fe}$ is also present with the highest proportion, followed by $\mathrm{Ca}, \mathrm{Cl}, \mathrm{P}, \mathrm{K}, \mathrm{S}, \mathrm{Mg}, \mathrm{Na}$, and finally $\mathrm{Si}$.

$\mathrm{Fe}, \mathrm{Ca}, \mathrm{Na}, \mathrm{K}, \mathrm{Si}, \mathrm{Mg}, \mathrm{P}, \mathrm{S}$, and $\mathrm{Cl}$ proportions of treated and native radulae are non-normal distributed. Between treated and native radulae, Wilcoxon test detected no significant difference in Fe and K, but significant difference in $\mathrm{Na}, \mathrm{Mg}, \mathrm{Si}, \mathrm{P}, \mathrm{Cl}$, and $\mathrm{Ca}$ (see Table 2).

\section{Young's modulus and hardness}


Both $\mathrm{E}$ and $\mathrm{H}$ values of the treated and the native group are non-normally distributed. The native radulae have higher $\mathrm{E}$ and $\mathrm{H}$ values than the treated radulae. Wilcoxon test detected significant difference for $\mathrm{E}$ and $\mathrm{H}$ between treated and native radulae (see Table 2).

\section{Breaking force and stress}

Breaking force and breaking stress values at different testing condition (dry, wet) are normally distributed. Between dry and wet condition, $t$ test detected significant differences for force and stress. Breaking force and stress are higher for wet teeth than for dry ones (see Table 2).

Breaking force and stress obtained from radulae, sorted to the treated dry, treated wet, native dry, or the native wet group are normally distributed. Highest force must be exerted to break teeth of the treated wet radulae, followed by native wet, native dry, and finally treated dry ones. ANOVA detected significant differences between these groups (see Table 2).

Highest breaking stress was calculated for the treated wet radulae, followed by native wet, treated dry, and finally native dry ones. ANOVA detected significant differences between these groups (see Table 2).

\section{Ontogenetic zones}

\section{Elemental proportions}

Native. For native radulae, the highest proportion (see Table 3) of all elements was found in the working zone, followed by the mineralization zone, and finally radular sack. The same pattern was detected for $\mathrm{Fe}, \mathrm{P}, \mathrm{Si}$, and $\mathrm{Mg}$ proportions. For $\mathrm{Na}, \mathrm{K}$, and $\mathrm{Ca}$, the highest proportions were determined for the working zone, followed by the radular sack, and finally mineralization zone. For S and $\mathrm{Cl}$, the highest proportions were found in the mineralization zone, followed by the radular sack, and finally working zone. Elemental proportions of each element for each zone (radular sack, mineralization zone, working zone) are nonnormally distributed and Kruskal-Wallis test detected significant difference in the proportions of each element between radular sack, mineralization zone, and working zone (see Table 3). 
Table 3

For each zone (radular sack, mineralization zone, and working zone) sorted to condition (native or treated). Mean, standard deviation (Sd), and quantity ( $n$ ) $c$ areas (by EDX and nanoindentation) or quantity of broken teeth (by breaking force experiments) for the following parameters are given: (a) proportions, given i $\mathrm{S}, \mathrm{Cl}, \mathrm{K}, \mathrm{Ca}$, Fe, and all elements. Differences between the zones for each condition were tested by Kruskal-Wallis test (orange $\mathrm{p}$-values = highly significant). (b $(\mathrm{E})$ and hardness $(\mathrm{H})$, given in GPa. Differences between the zones for each condition were tested by ANOVA (orange p-values = highly significant). (c) Breakins $\mathrm{mN}$, and breaking stress (Bs), given in MPa. Differences between the zones for each condition (native dry, native wet, treated dry, or treated wet) were tested by (black p-values $=$ not significant)

\begin{tabular}{|c|c|c|c|c|c|c|c|c|c|c|c|c|c|c|}
\hline \multirow[t]{2}{*}{ Parameter } & \multirow[t]{2}{*}{ Condition } & \multicolumn{4}{|c|}{ Radular sack } & \multicolumn{4}{|c|}{ Mineralization zone } & \multicolumn{4}{|c|}{ Working zone } & \multirow{2}{*}{$\begin{array}{l}\begin{array}{l}\text { Results fi } \\
\text { Wallis }\end{array} \\
\text { ChiSquar }\end{array}$} \\
\hline & & Sum & Mean & Sd & $n$ & Sum & Mean & Sd & $n$ & Sum & Mean & Sd & $n$ & \\
\hline $\mathrm{Na}$ & Native & 16.09 & 0.03 & 0.19 & 637 & 5.31 & 0.01 & 0.12 & 797 & 43.62 & 0.07 & 0.38 & 640 & 27.6204 \\
\hline $\mathrm{Mg}$ & Native & 0.00 & 0.00 & 0.00 & 637 & 7.92 & 0.01 & 0.09 & 797 & 39.18 & 0.06 & 0.24 & 640 & 80.0754 \\
\hline $\mathrm{Si}$ & Native & 0.00 & 0.00 & 0.00 & 637 & 0.32 & 0.00 & 0.00 & 797 & 0.84 & 0.00 & 0.01 & 640 & 10.2193 \\
\hline$P$ & Native & 1.34 & 0.00 & 0.04 & 637 & 67.00 & 0.08 & 0.43 & 797 & 101.85 & 0.16 & 0.67 & 640 & 41.7880 \\
\hline S & Native & 4.12 & 0.01 & 0.03 & 637 & 34.63 & 0.04 & 0.12 & 797 & 1.08 & 0.00 & 0.01 & 640 & 122.3041 \\
\hline $\mathrm{Cl}$ & Native & 0.00 & 0.00 & 0.00 & 637 & 8.18 & 0.01 & 0.05 & 797 & 0.06 & 0.00 & 0.00 & 640 & 76.9271 \\
\hline K & Native & 0.10 & 0.00 & 0.00 & 637 & 0.00 & 0.00 & 0.00 & 797 & 5.00 & 0.01 & 0.06 & 640 & 34.5237 \\
\hline $\mathrm{Ca}$ & Native & 312.58 & 0.49 & 0.96 & 637 & 1562.26 & 1.96 & 2.93 & 797 & 1294.83 & 2.02 & 2.26 & 640 & 182.6653 \\
\hline $\mathrm{Fe}$ & Native & 176.73 & 0.28 & 1.12 & 637 & 1492.93 & 1.87 & 4.94 & 797 & 2390.78 & 3.74 & 8.50 & 640 & 66.3440 \\
\hline $\begin{array}{l}\text { All } \\
\text { elements }\end{array}$ & Native & 510.96 & 0.80 & 1.79 & 637 & 3178.55 & 3.99 & 7.59 & 797 & 3877.23 & 6.06 & 10.71 & 640 & 171.8470 \\
\hline $\mathrm{Na}$ & Treated & 0.00 & 0.00 & 0.00 & 638 & 0.00 & 0.00 & 0.00 & 796 & 0.90 & 0.00 & 0.03 & 634 & 4.5322 \\
\hline $\mathrm{Mg}$ & Treated & 1.04 & 0.00 & 0.04 & 638 & 0.00 & 0.00 & 0.00 & 796 & 0.20 & 0.00 & 0.01 & 634 & 1.2553 \\
\hline $\mathrm{Si}$ & Treated & 0.10 & 0.00 & 0.00 & 638 & 0.00 & 0.00 & 0.00 & 796 & 0.00 & 0.00 & 0.00 & 634 & 2.2445 \\
\hline$P$ & Treated & 0.00 & 0.00 & 0.00 & 638 & 1.61 & 0.00 & 0.04 & 796 & 0.00 & 0.00 & 0.00 & 634 & 3.1895 \\
\hline S & Treated & 0.36 & 0.00 & 0.01 & 638 & 0.93 & 0.00 & 0.02 & 796 & 0.00 & 0.00 & 0.00 & 634 & 3.7718 \\
\hline $\mathrm{Cl}$ & Treated & 0.11 & 0.00 & 0.00 & 638 & 1.61 & 0.00 & 0.02 & 796 & 0.06 & 0.00 & 0.00 & 634 & 14.7670 \\
\hline K & Treated & 0.10 & 0.00 & 0.00 & 638 & 0.00 & 0.00 & 0.00 & 796 & 1.25 & 0.00 & 0.02 & 634 & 14.6396 \\
\hline $\mathrm{Ca}$ & Treated & 12.83 & 0.02 & 0.11 & 638 & 38.60 & 0.05 & 0.21 & 796 & 57.94 & 0.09 & 0.33 & 634 & 28.0213 \\
\hline $\mathrm{Fe}$ & Treated & 191.86 & 0.30 & 1.21 & 638 & 1640.56 & 2.06 & 5.28 & 796 & 2649.28 & 4.18 & 9.18 & 634 & 66.5291 \\
\hline \multirow[t]{3}{*}{$\begin{array}{l}\text { All } \\
\text { elements }\end{array}$} & Treated & 206.41 & 0.32 & 1.21 & 638 & 1683.30 & 2.11 & 5.28 & 796 & 2709.64 & 4.27 & 9.23 & 634 & 85.4997 \\
\hline & & & & & & & & & & & & & & Results $\mathrm{fr}$ \\
\hline & & & & & & & & & & & & & & F Ratio \\
\hline $\mathrm{H}$ & Native & & 0.55 & 0.40 & 637 & & 1.53 & 0.84 & 797 & & 2.10 & 0.81 & 640 & 749.4349 \\
\hline$E$ & Native & & 4.39 & 3.07 & 637 & & 12.03 & 6.36 & 797 & & 16.77 & 6.17 & 640 & 827.3774 \\
\hline $\mathrm{H}$ & Treated & & 0.44 & 0.28 & 638 & & 1.16 & 0.69 & 796 & & 1.53 & 0.89 & 634 & 444.0553 \\
\hline \multirow[t]{3}{*}{$E$} & Treated & & 3.49 & 2.12 & 638 & & 8.05 & 4.92 & 796 & & 11.82 & 6.81 & 634 & 443.8665 \\
\hline & & & & & & & & & & & & & & $\begin{array}{l}\text { Results } \mathrm{fr} \\
\text { Wallis }\end{array}$ \\
\hline & & & & & & & & & & & & & & ChiSquar \\
\hline $\mathrm{Bf}$ & $\begin{array}{l}\text { Native } \\
\text { dry }\end{array}$ & & 55.72 & 48.75 & 160 & & 170.25 & 165.09 & 151 & & 296.21 & 264.24 & 136 & 195.3931 \\
\hline
\end{tabular}




\begin{tabular}{|c|c|c|c|c|c|c|c|c|c|c|c|c|c|c|}
\hline \multirow[t]{2}{*}{ Parameter } & \multirow[t]{2}{*}{ Condition } & \multicolumn{4}{|c|}{ Radular sack } & \multicolumn{4}{|c|}{ Mineralization zone } & \multicolumn{4}{|c|}{ Working zone } & \multirow{2}{*}{$\begin{array}{l}\begin{array}{l}\text { Results fi } \\
\text { Wallis }\end{array} \\
\text { ChiSquar }\end{array}$} \\
\hline & & Sum & Mean & Sd & $n$ & Sum & Mean & Sd & $n$ & Sum & Mean & $\mathrm{Sd}$ & $n$ & \\
\hline $\mathrm{Bf}$ & $\begin{array}{l}\text { Native } \\
\text { wet }\end{array}$ & & 166.68 & 116.03 & 58 & & 433.48 & 294.42 & 77 & & 662.12 & 472.92 & 86 & 51.3350 \\
\hline Bs & $\begin{array}{l}\text { Native } \\
\text { dry }\end{array}$ & & 130.76 & 62.38 & 68 & & 272.30 & 78.68 & 86 & & 354.21 & 71.53 & 78 & 142.8282 \\
\hline Bs & $\begin{array}{l}\text { Native } \\
\text { wet }\end{array}$ & & 452.78 & 216.64 & 41 & & 863.75 & 411.53 & 56 & & 1125.43 & 607.26 & 58 & 34.5874 \\
\hline $\mathrm{Bf}$ & $\begin{array}{l}\text { Treated } \\
\text { dry }\end{array}$ & & 35.12 & 29.71 & 159 & & 98.17 & 96.87 & 142 & & 173.48 & 150.37 & 132 & 187.9531 \\
\hline $\mathrm{Bf}$ & $\begin{array}{l}\text { Treated } \\
\text { wet }\end{array}$ & & 210.08 & 156.47 & 54 & & 568.14 & 374.50 & 68 & & 850.62 & 614.00 & 78 & 36.7029 \\
\hline Bs & $\begin{array}{l}\text { Treated } \\
\text { dry }\end{array}$ & & 273.77 & 142.42 & 67 & & 522.58 & 215.57 & 79 & & 684.40 & 275.23 & 78 & 84.3258 \\
\hline Bs & $\begin{array}{l}\text { Treated } \\
\text { wet }\end{array}$ & & 591.94 & 264.89 & 41 & & 1382.89 & 361.75 & 54 & & 1961.11 & 662.58 & 58 & 89.3619 \\
\hline
\end{tabular}

Treated. For treated radulae, the highest proportion (see Table 3) of all elements was determined for the working zone, followed by the mineralization zone, and finally radular sack. The same pattern was found for Fe and Ca. For K, the highest proportion was detected in the working zone, followed by the radular sack, and finally mineralization zone. For $\mathrm{Cl}$ and $\mathrm{S}$, the highest proportion was found in the mineralization zone, followed by the radular sack, and finally working zone. For Mg, the highest proportion was detected in the working zone, followed by the radular sack, and finally mineralization zone. For Na, Si, and $\mathrm{P}$, we only received data from one zone for each element. Elemental proportions of each element for each zone (radular sack, mineralization zone, working zone) are non-normally distributed and Kruskal-Wallis test determined no significant difference between proportions of the radular sack, mineralization zone, and working zone for $\mathrm{Na}, \mathrm{Mg}, \mathrm{Si}, \mathrm{P}$, and $\mathrm{S}$ (see Table 3). Significant differences were found for $\mathrm{Cl}, \mathrm{K}, \mathrm{Ca}$, Fe, and all elements pooled together.

\section{Young's modulus and hardness}

For native and treated radulae, the highest $\mathrm{E}$ and $\mathrm{H}$ (see Table 3) were found in the working zone, followed by the mineralization zone, and finally the radular sack. The $\mathrm{E}$ and $\mathrm{H}$ for each zone (radular sack, mineralization zone, working zone) are normally distributed and ANOVA detected significant difference between radular sack, mineralization zone, and working zone of either treated or native radulae (see Table 3).

\section{Breaking force and stress}

Breaking force and stress sorted by zone for each condition (treated dry, treated wet, native dry, or the native wet) are non-normally distributed. For each parameter, Kruskal-Wallis test detected significant differences (see Table 3). The highest forces and the highest stress were calculated for breaking teeth of the working zone, followed by the mineralization zone, and finally the radular sack for each condition (see Table 3 ).

\section{Tooth types in whole radula Elemental proportions}

Native. The highest proportions (see Supplementary Table 1) of all elements, Ca, and Si were detected in the lateral teeth II, followed by the marginal teeth, lateral teeth I, and finally central teeth. For Fe, the highest proportions were found in the lateral teeth II, followed by marginal teeth, central teeth, and finally lateral teeth I. For K, lateral teeth II have the highest proportions, followed by central teeth, marginal teeth, and finally lateral teeth I. Cl was mostly present in lateral teeth II, succeeded by lateral teeth I, marginal teeth, and finally central teeth. The highest proportions of S were measured in the marginal teeth, followed by lateral teeth II, lateral teeth I, and finally central teeth. Na and P were only detected in the lateral teeth II, here with the highest proportions, and in the marginal teeth. Mg was found only in the lateral teeth II.

Elemental proportions of each element for each tooth type (central tooth, lateral tooth I, lateral tooth II, marginal tooth) are non-normal distributed and KruskalWallis test detected in most cases significant differences (except for $\mathrm{Si}, \mathrm{S}$, and $\mathrm{Cl}$ ) between proportions of each tooth type for each element (see Supplementary Table 1).

Treated. For the treated radulae, the highest proportions (see Supplementary Table 1) of all elements, Fe, and Ca were detected in the lateral teeth II, followed by the marginal teeth, central teeth, and finally lateral teeth I. K was determined in the lateral teeth II with the highest proportion, followed by marginal teeth, and central teeth, but not in the lateral teeth I. S was not detected in the marginal teeth; its highest proportions were found in the lateral teeth I, followed by lateral teeth II, and central teeth. P was not detected in marginals and centrals; its highest proportions were found in lateral teeth I followed by lateral teeth II. Si was only determined in marginal teeth, $\mathrm{Mg}$ in central teeth, and $\mathrm{Na}$ in lateral teeth II.

Elemental proportions of each element for each tooth type (central tooth, lateral tooth I, lateral tooth II, marginal tooth) are non-normally distributed and Kruskal-Wallis test detected in most cases no significant differences (except for $\mathrm{Mg}$, Ca, Fe, and all elements) between proportions in each tooth type for each element (see Supplementary Table 1). Wilcoxon test (see Supplementary Table 2) detected significant differences between proportions of all elements, Ca, and $\mathrm{S}$ in treated and native radulae for each tooth type and no significant differences between Fe and $\mathrm{K}$ proportions in treated and native radulae for each tooth type. For all other elements, the picture is rather puzzling. 


\section{Young's modulus and hardness}

For treated and native groups, $\mathrm{E}$ and $\mathrm{H}$ values for each individual tooth type are normally distributed. The hardest and stiffest teeth were always (for treated and native radulae) the lateral teeth II, followed by marginal teeth, lateral teeth I, and finally central teeth (see Supplementary Table 1). ANOVA detected significant differences for $\mathrm{E}$ and $\mathrm{H}$ between the tooth types within the either treated or native group (see Supplementary Table 1). Tukey-Kramer test revealed significant differences between $\mathrm{E}$ and $\mathrm{H}$ of treated and native radulae for each tooth type (see Supplementary Table 2).

\section{Breaking force and stress}

Breaking force and breaking stress sorted by tooth type for each condition (treated dry, treated wet, native dry, or the native wet) are normally distributed. For breaking force, ANOVA detected significant differences. For breaking stress, $t$ test also detected significant differences (see Supplementary Table 1 ).

For all conditions (treated dry, treated wet, native dry, or the native wet), the highest forces were needed for breaking lateral teeth II, followed by central teeth, lateral teeth I, and finally marginal teeth. The highest breaking stresses were calculated for lateral teeth II and the lowest one for marginal teeth (see Supplementary Table 1).

Tukey-Kramer test revealed significant differences in most cases for breaking force and breaking stress of each tooth type between dry or wet, treated or native condition (see Supplementary Table 2).

\section{Tooth types in each ontogenetic zone Elemental proportions}

Sorted according to the tooth type and zone, elements are non-normal distributed. Regarding all elements, the Wilcoxon method (see Supplementary Table 5) detected significant differences between treated and native marginal teeth, lateral teeth II, lateral teeth I, and central teeth of both working and mineralization zones, but only between treated and native lateral teeth II and marginal teeth of the radular sack. For Fe and $\mathrm{K}$, no significant differences between treated and native teeth were detected. For $\mathrm{Ca}$, all teeth of both working and mineralization zones were significantly different. Only the central teeth or radular sack were not different. For $\mathrm{Cl}$, significant differences were detected in the mineralization zone for the lateral tooth I, lateral tooth II, and marginal tooth. For S, significant differences were detected for each tooth type of the mineralization zone. For the radular sack, only the lateral tooth I and marginal teeth differed significantly. For the working zone, only the lateral teeth II differed significantly. For P and Mg, lateral teeth II differed significantly in the working zone and mineralization zone. For $\mathrm{Si}$, differences were detected for lateral teeth II of the working zone and for marginal teeth of the mineralization zone. For $\mathrm{Na}$, treated and native lateral teeth II differed significantly in each zone. In the radular sack, marginal teeth differed.

Native. Whole element content was always highest in lateral tooth II in every zone (see Supplementary Table 3). In the radular sack, it is followed by marginal tooth, central tooth, and finally lateral tooth I. In the mineralization and working zones, it is succeeded by the central tooth, lateral tooth I, and finally marginal tooth.

When analyzing the individual elements, Fe was present in the highest proportions, however, only in lateral tooth II (Figure 5). Here proportions increased during ontogeny. For all other teeth, Fe was detected in very small proportions and the distribution does not seem to follow a clear pattern. In the central teeth, the proportions increased during ontogeny. In the lateral tooth I, they decreased from the radular sack to the working zone. For the marginal teeth, Fe proportions first increased from the radular sack to the mineralization zone, but then decreased in the working zone.

The second most abundant element is Ca. In every zone, the lateral tooth II always contains the highest proportions of Ca (Figure 5). In the radular sack, it is followed by the marginal tooth, central tooth, and finally lateral tooth I. In the mineralization and working zones it is followed by the central tooth, lateral tooth $\mathrm{I}$, and finally marginal tooth. For the central tooth, lateral tooth I, and marginal tooth, Ca proportions increased during ontogeny. For the lateral tooth II, Ca first increased from the radular sack to the mineralization zone, but then decreased in the working zone.

However, for many elements, especially those that are rarely detected as trace elements, $(\mathrm{Na}, \mathrm{Si}, \mathrm{K}, \mathrm{Mg}, \mathrm{P}, \mathrm{S}, \mathrm{Cl})$, the elemental distributions are rather puzzling and no clear gradients during ontogeny could be detected for the individual tooth types (Figure 5; here $\mathrm{Na}$, Mg, Si, P, S, Cl, and K are summarized as 'Se'). Mg was only detected in the lateral tooth II, its proportions slightly increased during ontogeny. P was detected in the lateral tooth II and marginal tooth, increasing during ontogeny. $\mathrm{S}$ and $\mathrm{Cl}$ proportions first increased from the radular sack to the mineralization zone, but then decreased in the working zone in each tooth type.

Treated. The whole element content was again the highest one in the lateral tooth II in each zone (see Supplementary Table 3). In each zone, it is decreased in the series central tooth $\rightarrow$ marginal tooth $->$ lateral tooth $\mathrm{I}$.

Fe was present in the highest proportions, however, only in the lateral tooth II (Figure 5). Its high proportions were detected in the working zone, followed by the mineralization zone, and finally the radular sack. For all other teeth, Fe was detected in very small proportions and its distribution does not seem to follow a clear pattern, but it was the same pattern, as the one determined in native teeth: for central teeth, proportions increased during ontogeny. For the lateral tooth I, the amount of Fe decreased from the radular sack to the working zone. For the marginal teeth, Fe proportions first increased from the radular sack to the mineralization zone, but then decreased in the working zone.

Ca was less abundant than in native radulae (Figure 5). However, in each zone, the lateral tooth II contained the highest proportions of Ca. The distribution pattern differed from the native radulae. In the radular sack and working zone, it is followed by the central tooth, marginal tooth, and finally lateral tooth I. In the mineralization zone, it is followed by the marginal tooth, central tooth, and finally lateral tooth I. For the central tooth, lateral tooth II, and marginal tooth, 
the highest Ca proportions were detected in the working zone, followed by mineralization zone, and finally radular sack. For the lateral tooth I, Ca was only detected in the mineralization zone.

$\mathrm{Na}, \mathrm{Mg}, \mathrm{Si}, \mathrm{P}, \mathrm{S}, \mathrm{Cl}$, K were only very occasionally detected in treated radulae (Figure 5, here $\mathrm{Na}, \mathrm{Mg}, \mathrm{Si}, \mathrm{P}, \mathrm{S}, \mathrm{Cl}$, and K are summarized as 'Se').

\section{Young's modulus and hardness}

Sorted to tooth type and zone, both $\mathrm{E}$ and $\mathrm{H}$ data were normally distributed. The Tukey-Kramer method (see Supplementary Table 5) detected significant differences between treated and native marginal teeth, lateral teeth II, lateral teeth I, and central teeth of the working zone. For the mineralization zone, significant differences were detected between native and treated lateral teeth II, lateral teeth I, and marginal teeth. For the radular sack, significant differences were detected between native and treated lateral teeth II, and marginal teeth.

Native. Each tooth type became stiffer and harder during ontogeny (see Figure 5 and Supplementary Table 3). In each zone, the lateral tooth II was always the hardest and stiffest one. In the working zone, it was followed by the lateral tooth I, central tooth, and finally marginal tooth. In the mineralization zone and radular sack, it was followed by marginal tooth, lateral tooth I, and finally central tooth.

Treated. Each tooth type was the stiffest and hardest in the working zone, followed by the mineralization zone, and finally radular sack (see Figure 5 and Supplementary Table 3). In each zone, the lateral tooth II was always the hardest and stiffest one. Then, it was followed by the central tooth, lateral tooth I, and marginal tooth in the working zone; by the marginal tooth, lateral tooth I, and central tooth in the mineralization zone and radular sack.

\section{Breaking force and stress}

For each condition (treated dry, treated wet, native dry, or the native wet) and sorted by tooth type and zone, breaking force and breaking stress were nonnormally distributed. In the most cases (see Supplementary Table 5), significant differences between the treated and native tooth types in every zone were detected.

Native. Tested under dry condition, the highest force (see Figure $6 \mathrm{c}$ and Supplementary Table 4) must be exerted to break the lateral teeth II, followed by central teeth, lateral teeth I, and finally marginal teeth in each zone. Tested under wet condition, the same pattern was found for teeth of the mineralization and working zones. For the wet radular sack, the lateral teeth II were, however, followed by the lateral teeth I, central teeth, and finally marginal teeth. The breaking stress did not fully relate to this pattern (see Figure 7a and Supplementary Table 4). For every dry radular zone, the highest breaking stress was calculated for the marginal teeth and the lowest one for the lateral teeth II. Tested under wet condition, the highest stress was found for the lateral teeth II and the lowest one for the marginal teeth for each zone.

Treated. Tested under dry condition, the highest force (see Figure 6c and Supplementary Table 4) must be exerted to break lateral teeth II, followed again by central teeth, lateral teeth I, and finally marginal teeth of each zone. Tested under wet condition, the same pattern was found for teeth of the radular sack and mineralization zone. For the wet working zone, the lateral teeth II were followed by lateral teeth I, central teeth, and finally marginal teeth. The breaking stress did not fully relate to this pattern (Figure 7a). For each zone, the highest breaking stress was calculated for the marginal teeth and the lowest one for the lateral teeth II. Tested under wet condition, the highest stress was found for lateral teeth II and the lowest one for the marginal teeth for each zone.

\section{Tooth areas of failure}

Certain mechanical behaviours were observed during breaking stress experiments (see Supplementary Figure 1 and Table 6): some teeth broke close to the membrane at their basis or their styli, some were completely crushed, broke underneath their junction zone or at their junction zone. In some cases, it was impossible to break teeth due to bending or twisting.

Native and treated radulae exhibited similar mechanical behaviour: wet marginal teeth, lateral teeth I, and central teeth bended in most experiments and thus did not fail, especially younger teeth of the radular sack and mineralization zone. When breaking occurred, they either broke at their basis or stylus (Figures $7 \mathrm{~b}$, c). Wet lateral teeth II of the working and mineralization zone failed underneath their junction zone. In the radular sack, these teeth were, however, capable of bending (in $36 \%$ of cases). Dry marginal teeth failed in all cases at their basis, dry lateral teeth I and central teeth were always completely crushed. Dry lateral teeth II of the working and mineralization zones always failed at their junction zone (Figures $7 \mathrm{~b}, \mathrm{c}$ ). In the radular sack, these teeth failed in 24 cases at their junction zone and were crushed in 23 cases.

\section{Properties within each tooth type and ontogenetic zone Elemental proportions}

Overall, no gradients within teeth sorted to ontogenetic zone were detected for $\mathrm{Na}$, Mg, Si, P, S, Cl, and K, since these elements were only occasionally detected in native and treated radulae (see Figure 8, here these elements are summarized as 'Se', and Supplementary Table 7). We therefore focus on Ca, Fe, and proportion of all elements. Sorted to the tooth type, tooth structure (basis, stylus, cusp), and zone, these elements were normally distributed.

Native. For Ca, no clear gradients were detected (see Figure 8 and Supplementary Table 7) within central teeth and lateral tooth I. However the lateral tooth II and marginal tooth exhibited gradients. For the lateral tooth II, it was already present in the radular sack (here the basis contains the highest proportion of Ca, followed by the cusp, and finally the stylus). In the mineralization and working zone, the cusps contained most Ca, followed by the stylus, and finally the basis. For the marginal teeth, gradients were detected in the mineralization and working zones. In both zones, the stylus contained the most Ca, followed by the cusp, and finally the basis. For Fe, a gradient for only lateral teeth II (Figure 8) was detected; the cusps contained the highest Fe proportions, followed by the stylus and finally by the basis in each zone.

Page $10 / 30$ 
Treated. With the one exception (lateral tooth II of the working zone), all teeth were homogenous in their Ca distribution (see Figure 8 and Supplementary Table 7). For Fe, the same pattern as in native radulae was detected (Figure 8).

\section{Young's modulus and hardness}

Sorted to the tooth type, tooth structure (basis, stylus, cusp), and zone, E and H were normally distributed. Within each tooth type, with some exceptions in the radular sack, $t$ test (for the central and lateral tooth I) or ANOVA (for the lateral tooth II and marginal tooth) detected significant differences between basis, stylus, and cusps for treated and native radulae (see Supplementary Table 7).

Native In the radular sack, no gradients within the central tooth (see Figure 8 and Supplementary Table 7) were detected. They were detectable for the lateral tooth I and marginal tooth and pronounced in the lateral tooth II. The cusp of the tooth was always the stiffest and hardest part and the stylus was much softer. For the lateral tooth II and marginal tooth $\mathrm{E}$ and $\mathrm{H}$ of the tooth basis were measured. In the marginal teeth, the basis was softer and more flexible than the stylus, but for the lateral teeth II, the stylus was softer than the basis. In the mineralization and working zones, all teeth had pronounced gradients from the cusp, as the stiffest and hardest part, across the stylus to the basis, as the softest and most flexible part.

Treated. In the radular sack, gradients within the tooth (see Figure 8 and Supplementary Table 7) were not detected for the lateral tooth I and the marginal tooth. They were detected for the central tooth and already pronounced in the lateral tooth II. Here the cusp was again the stiffest and hardest part and the stylus was much softer. In the lateral teeth II, the stylus was again softer than the basis. In the mineralization and working zones, gradients were similar to those of the native group.

\section{Ontogenetic changes between the individual tooth rows}

E and $\mathrm{H}$ values (see Supplementary Table 8) of all central tooth parts, all lateral tooth I parts, lateral tooth II cusp and basis, and all marginal tooth parts rather increased gradually during ontogeny (Figure 3 and Supplementary Table 9). E and $\mathrm{H}$ values of the lateral tooth II stylus increased more strongly from row 17 to row 22. Fe proportions, proportion of all elements (see Figures 4, 9, and Supplementary Table 9), and slightly distributed elements ('Se'; see Figure 10 and Supplementary Table 9) in each tooth part gradually increased. Ca proportions in the lateral teeth II, first increased during ontogeny and decreased after the row 25 (see Figure 3 and Supplementary Table 9). In the treated radulae, the E and $\mathrm{H}$ values of all parts of the central and lateral teeth I, the stylus and bases of the lateral teeth II, and all parts of the marginals did not increase much (see Figure 4 and Supplementary Table 9). The increase in E and $\mathrm{H}$ values of the lateral teeth II cusps seems to be not affected by treatment. The Ca content of the treated lateral teeth II fluctuates highly between tooth rows. Proportions of all elements and the slightly distributed elements (Se) were significantly reduced in each tooth row (see Figures 9, 10, and Supplementary Table 9).

\section{Relationship between elements, mechanical properties, and mechanical behaviour For all tooth types together (treated and native)}

$\mathrm{H}$ and $\mathrm{E}$ were highly correlated ( $r=0.99$; see Supplementary Table 10 and Supplementary Figures $2-3)$. $\mathrm{H}$ correlates with Fe proportion by a correlation coefficient of 0.76 and with $\mathrm{Ca}$ with the one of 0.68 . For $\mathrm{E}$, a row-wise correlation with $\mathrm{Fe}$ of 0.70 and with $\mathrm{Ca}$ of 0.70 was obtained. For $\mathrm{Na}$, $\mathrm{Mg}$, $\mathrm{Si}$, $\mathrm{P}, \mathrm{S}$, $\mathrm{Cl}$, and $\mathrm{K}$, low correlation coefficients were determined. When relating the mean values of measured mechanical properties $(\mathrm{H}$ and $\mathrm{E})$, element proportions (Ca and Fe) to the mean values of Bf and Bs (see Supplementary Table 21 and Supplementary Figures 2-3), it was detected, that H, E, Fe, Ca, dry Bf, wet Bf, and wet Bs correlated with each other. Dry Bs correlated with wet Bs to 0.74 and to Fe with 0.34 , but to low correlation coefficients with $\mathrm{H}$, E, Ca, dry Bf, and wet Bf.

\section{Sorted to treatment}

For all native teeth together, $\mathrm{H}$ and $\mathrm{E}$ highly correlated $(r=0.99$; see Supplementary Table 11). $\mathrm{H}$ correlated with Fe proportion by a correlation coefficient of 0.70 and with $\mathrm{Ca}$ with the one of 0.71 . For $\mathrm{E}$, correlation factors with Fe and Ca of 0.69 were calculated. For $\mathrm{Na}, \mathrm{Mg}, \mathrm{Si}, \mathrm{P}, \mathrm{S}, \mathrm{Cl}$, and K, small correlation coefficients were determined. For all treated teeth pooled together, $\mathrm{H}$ correlated with $\mathrm{E}(\mathrm{r}=0.94$; see Supplementary Table 12). $\mathrm{H}$ correlated with the Fe proportion by a correlation coefficient of 0.77 , but with Ca only with the one of 0.09 . Correlation of $E$ with Fe proportion was revealed with the correlation factor of 0.85 . With $\mathrm{Ca}$ it correlated only by the correlation factor of 0.10 . For $\mathrm{Na}, \mathrm{Mg}, \mathrm{Si}, \mathrm{P}, \mathrm{S}, \mathrm{Cl}$, and $\mathrm{K}$, very small correlation coefficients were determined.

\section{For every tooth type and sorted to treatment}

Central tooth, native. $\mathrm{H}$ and $\mathrm{E}$ highly correlated $(r=1.00$; see Supplementary Table 13). $\mathrm{H}$ and E correlated less with Ca proportion ( $r=0.32)$. All other determined correlation coefficients were very small. $\mathrm{H}, \mathrm{E}, \mathrm{Fe}, \mathrm{Ca}$, dry Bf, and wet Bf highly correlated: the highest correlation coefficient (1.00) was detected between $\mathrm{H}$ and $\mathrm{E}$ and the lowest one (0.97) between $\mathrm{Ca}$ and Fe proportions (see Supplementary Table 22).

Lateral tooth I, native. $\mathrm{H}$ highly correlated with $\mathrm{E}(\mathrm{r}=1.00$; see Supplementary Table 14). $\mathrm{H}$ and $\mathrm{E}$ correlated less with Ca proportion $(r=0.28)$. All other determined correlation coefficients were very small. H, E, Ca, dry Bf, and wet Bf highly correlated with each other (see Supplementary Table 23). Fe correlated with all other parameters with relatively low correlation coefficients $(0.38-0.49)$.

Lateral tooth II, native. $\mathrm{H}$ and $\mathrm{E}$ are highly correlated with each other $(r=0.99$; see Supplementary Table 15$)$. Both $\mathrm{H}$ and $\mathrm{E}$ are also highly correlated with the amount of $\mathrm{Fe}(\mathrm{r}$ with $\mathrm{H}=0.79$; $r$ with $\mathrm{E}=0.80$ ) and $\mathrm{Ca}(\mathrm{r}$ with $\mathrm{H}$ or $\mathrm{E}=0.73)$. They are less correlated with $\mathrm{P}(\mathrm{r}$ with $\mathrm{H}=0.29 ; \mathrm{r}$ with $\mathrm{E}=0.30)$. $\mathrm{H}, \mathrm{E}, \mathrm{Fe}, \mathrm{Ca}$, dry $\mathrm{Bf}$, and wet Bf highly correlate; the highest coefficient (1.00) was detected for $\mathrm{H}$ and $\mathrm{E}$ and the lowest ones between $\mathrm{Ca}$ and wet $\mathrm{Bf}(0.76)$ and between Ca and Fe (0.76) (see Supplementary Table 24). All other determined correlation coefficients are very small.

Marginal tooth, native. $\mathrm{H}$ and $\mathrm{E}$ are highly correlated with each other $(\mathrm{r}=0.99$; see Supplementary Table 16$)$. Both $\mathrm{H}$ and $\mathrm{E}$ only are slightly correlated with the amount of $\mathrm{Ca}$ ( $r$ with $\mathrm{H}=0.23$ or $\mathrm{E}=0.24$ ). $\mathrm{H}, \mathrm{E}, \mathrm{Ca}$, dry Bf, wet $\mathrm{Bf}$, dry Bs, and wet Bs highly correlate; the highest coefficient (1.00) was detected for $\mathrm{H}$ and $\mathrm{E}$ 
and the lowest ones between $\mathrm{Ca}$ and wet $\mathrm{Bf}(0.72)$ and between $\mathrm{H}$ and wet Bs (0.76) (see Supplementary Table 25). Fe negatively correlates with each parameter. All other determined correlation coefficients are very small.

Central tooth, treated. $\mathrm{H}$ and $\mathrm{E}$ are highly correlated with each other $(r=0.99$; see Supplementary Table 17$)$. $\mathrm{H}, \mathrm{E}, \mathrm{Ca}$, dry Bf, and wet Bf are highly correlated (see Supplementary Table 26). Fe negatively correlates with each parameter. All other correlation coefficients are very small.

Lateral tooth I, treated. $\mathrm{H}$ and $\mathrm{E}$ are highly correlated with each other $(r=0.99$; see Supplementary Table 18). $\mathrm{H}, \mathrm{E}$, dry Bf, and wet Bf highly are correlated (see Supplementary Table 27). Ca negatively correlates with each parameter: with $\mathrm{H}, \mathrm{E}$, dry Bf, and wet Bf at low negative coefficients (-0.17--0.21) and with Fe with a high negative coefficient $(-0.94)$. Fe correlates with all parameters with a low positive coefficient $(0.48-0.52)$. All other correlation coefficients are very small.

Lateral tooth II, treated. $\mathrm{H}$ and $\mathrm{E}$ are highly correlated with each other $(\mathrm{r}=0.92$; see Supplementary Table 19$)$. Both $\mathrm{E}$ and $\mathrm{H}$ are highly correlated with the amount of $\mathrm{Fe}$ ( $\mathrm{r}$ with $\mathrm{H}=0.82$; $r$ with $\mathrm{E}=0.94) . \mathrm{H}, \mathrm{E}, \mathrm{Fe}, \mathrm{Ca}$, dry Bf, and wet $\mathrm{Bf}$ are highly correlated: the highest coefficient (1.00) was detected for $\mathrm{H}$ and dry $\mathrm{Bs}$ and the lowest one between $\mathrm{Ca}$ and $\mathrm{H}(0.86)$ (see Supplementary Table 28). All other correlation coefficients are very small.

Marginal tooth, treated. $\mathrm{H}$ and $\mathrm{E}$ are highly correlated with each other $(r=0.92$; see Supplementary Table 20). $\mathrm{H}, \mathrm{E}, \mathrm{Ca}$, dry Bf, wet Bf, dry Bs, and wet Bs are highly correlated: the highest coefficients (1.00) were detected between wet Bf and $\mathrm{E}$ as well as $\mathrm{Ca}$ and $\mathrm{E}$; the lowest ones between dry $\mathrm{Bf}$ and wet $\mathrm{Bs}(0.81)$ as well as wet and dry Bs (0.81) (see Supplementary Table 29). Fe negatively correlates with each parameter. All other correlation coefficients are very small.

3-way ANOVA revealed that state (native or treated), tooth type, and radular zone all have significant effects on $\mathrm{E}$ and $\mathrm{H}$ values ( $\mathrm{p}<0.0001$ for each, see Supplementary Figure 4 and Supplementary Tables 30-31). 4-ANOVA detected that state (native or treated), tooth type, condition (dry or wet), and radular zone all have the same significant effect on $\mathrm{E}$ and $\mathrm{H}$ values $(\mathrm{p}<0.0001$ for each, see Supplementary Figure 5 and Supplementary Tables $32-33)$. PCA for marginals, centrals, and lateral teeth I detected no clusters (see Supplementary Figure 6).

\section{Discussion}

\section{Elements detected}

The mineralization and transformations during maturation in the dominant lateral tooth (termed lateral tooth II in this study) of iron and non-iron minerals were very well investigated in the last decades [see e.g. $13,18,42,43,44,53,54,55,56,57,58,59$ ]. It was previously determined that after the secretion and formation of the three-dimensional alpha-chitin matrix with the associated proteins, which are possibly involved in the biomineralization process [60], various iron oxide phases are incorporated into the matrix [see also 61]. First ferrihydrite $\left(\mathrm{Fe}^{3+}{ }_{10} \mathrm{O}_{14}(\mathrm{OH})_{2}\right)$ is deposited in the junction zone and the margins of the tooth, before it also occurs in the leading part $[13,18,40,54,56,62]$. During maturation it is replaced by iron oxides and iron oxyhydroxide minerals, usually by magnetite $[63,64]$, in the cusps' leading part $[9,54,57,65,66]$. But in some taxa small proportions of lepidocrocite $(\gamma-\mathrm{FeOOH})[12,13,40,56,67,68 ; 69,70,71$, 72], goethite (alpha-FeOOH) [55, 73], or hydrated iron oxides (limonite) [74] were detected.

The distribution of magnetite seems to be taxon specific, in Chiton and Acanthopleura the posterior part of the dominant lateral tooth cusp is composed of magnetite whereas the anterior part is composed of apatite [12, 13, 56, 67, 71, 75, 76, 77]. In Cryptochiton, Cryptoplax, and Chaetopleura magnetite covers both posterior and anterior cusps' surfaces $[51,57,75,78]$ whereas the core is either composed of amorphous iron phosphate $[79,80]$, apatite $[9,70,73]$, or iron and/or magnesium phases [40, 72].

For Lepidochitona, due to our methodology, we are not capable of differentiating between the different iron oxide phases, since we were only able to determine the elemental distribution. But, [9] described that ferrihydrite deposition in the matrix is accompanied by colour change to red/brown and magnetite deposition by a change to glossy black. For Lepidochitona we would thus propose that from row 8 to 9 ferrihydrite is present and from row 10 on magnetite is dominant.

In Lepidochitona, the distribution of iron, observed in the dominant lateral tooth cusps, is rather similar to the pattern observed in Cryptochiton, Cryptoplax, and Chaetopleura [51, 57, 75, 78], as iron covers both the anterior and posterior parts of the cusp. Potentially, the occurrence of iron only in the posterior part is an apomorphic character of the Chitonida (for systematics of Polyplacophora, see [81]) and on anterior and posterior part is plesiomorphic. However, this awaits further investigations and a broader taxon-sampling.

In past studies about the radular tooth ontogeny, the dominant lateral tooth was in focus. As described by [82], ferritin is present in the haemolymph and delivered to the superior epithelia cells of the radular sack, which covers the dominant lateral tooth cusps. Afterwards a pore is penetrated into the cusp and stylus [77, 83]. Thus, the stylus canal may potentially serve as a biomineralization delivery pathway [52]. The first depositions of iron were detected in the 'junction zone', the part between cusp and basis [51, 52], and therefore it was postulated that this region serves as repository for ions, which migrate during ontogeny to the cusp $[56,70,72,77,84]$. For Lepidochitona, we observed a slightly different pattern: in native radulae we found that the cusps are mineralized with iron first $(0.38 \pm 0.59 \%$ in row 6$)$. In row 7 , the cusps still contain the highest iron proportions $(0.52 \pm 0.38 \%)$, followed by the stylus $(0.15 \pm 0.05 \%)$, and finally the basis $(0.14 \pm 0.13 \%)$. These gradients in the iron distribution with the cusps, containing the highest proportions, followed by the stylus, and finally the basis continued until the tooth is mature in rows 28 or 29 .

The ontogenetic changes of the iron proportions were previously documented for Acanthopleura [56, 70, 71], Ischnochiton, Onithochiton, Plaxiphora [71], Cryptoplax [51], and Clavarizona [85]. In all of these taxa, iron proportions increase dramatically within very few rows in the magnetite region of the cusps and the junction zone. The junction zone sometimes loses its iron content during ontogeny again, whereas the anterior core region, the central/posterior core region, and the tooth basis rather increase their iron content gradually. For Lepidochitona, we were, due to the smallness of these teeth and our EDX methodology, which involved rather larger areas, not capable of clearly differentiating between the magnetite region, the anterior core region, and the

Page $12 / 30$ 
central/posterior core region [terms from 71]. Our points of measurements rather cover areas of all three zones in the cusp altogether. During ontogeny we determined a steady increase of iron content in the cusps. The stylus [which is equivalent to the 'tooth basis' in 71] and the basis also show a steady increase of iron, which is for the stylus in congruence with the previous results of [51] and [71].

In previous studies, iron contents of mature dominant lateral teeth were determined for (1) Acanthopleura with 59.2\% [12] or 62\% [56, 71] or few percent [70], (2) Plaxiphora with $86.6 \%$ [12] and 17-27\% or 66\% [71], (3) Cryptochiton 51.8\% [53] or up to 69\% [18], (4) Ischnochiton with 62\% [71], (5) Onithochiton with $66 \%$ [71], (6) Cryptoplax with 90 weight \% in the cap, 30 weight \% in the core, junction zone, and basis [51], and (7) Chiton with 97\% [62]. We detected for mature Lepidochitona teeth iron proportions (atomic ratio, atomic \%) of $\sim 30 \%$ in the cusps. However, it is rather difficult to compare percentages between studies, since in some publications weight percentages were studied, whereas in others atomic ratios were determined. Besides, methodology, sample preparation, and the analysed sample itself (whole radula or individual radular parts) strongly vary between individual studies.

The cores of the dominant lateral tooth, the region underneath the iron-containing tooth caps, can contain, besides of the organic matrix being present in the mineralized parts of teeth [13], some amount of phosphorus $[51,53,71,72,86]$ as iron phosphate $[40,79,80]$ or as apatitic calcium phosphate $[9,70,72,73$, $75,87]$, magnesium $[71,72]$, and fluor related to calcium $[67,87,88]$. It was reported that this tooth part is the least mineralized one in ontogeny [42]. In the posterior core region, calcium (max. 30 elemental \%) and phosphorus proportions (max. 18 elemental \%) increase dramatically within few rows, whereas calcium (max. $\sim 30$ elemental \%) and phosphorus (max. 20 elemental \%) content in the anterior core region increases gradually during ontogeny in Acanthopleura [70, 71] and Onithochiton [71]. In Acanthopleura and Onithochiton, calcium and phosphorus content also increase dramatically within few rows in the anterior core region, whereas magnesium content of all tooth areas, calcium and phosphorus content of the basis (termed here 'stylus') of Acanthopleura, the anterior core region, the central/posterior core region, and the basis (termed here 'stylus') of Ischnochiton and Plaxiphora increase their content gradually [71]. Additionally, silicon had been previously detected in the core, where the tooth also contains iron and phosphorus [9, 51, 71, 75]. In the junction zone, iron, phosphorus, and calcium were detected in higher proportions for Acanthopleura, Ischnochiton, Onithochiton, and Plaxiphora early in ontogeny (from row 8 on) [71] and at very low proportions before teeth become orange in colour [51]. Sulphur, deposited in ontogeny earlier than iron (before the onset of mineralization) in the junction zone and probably responsible for the yellow colour of teeth, was also previously detected [51]. It seems to be associated with the appearance of proteins and the tanning of the organic matrix [89]. Additionally, [85] detected zinc, potassium, fluorine, sulphur, sodium, and chlorine in radular segments of Clavarizona, [12] - calcium, phosphorus, magnesium, sulphur, sodium, zinc, potassium, aluminium, copper, and silicon in radulae of Acanthopleura and Plaxiphora, and [51] - magnesium (with max $\sim 5.5$ weight \% in the basis), potassium (with max 1.0 weight $\%$ in the basis), sodium (with $\max \sim 2.0$ weight $\%$ in the basis), silicon (with max $\sim 1.0$ weight $\%$ in the basis), aluminium (with max $\sim 0.5$ weight $\%$ in the basis), and sulphur (with max $\sim 0.8$ weight \% in the junction zone) in Cryptoplax. Calcium proportions of $\sim 5 \%$ were detected in the cusps of mature dominant lateral teeth of Lepidochitona: proportions decrease gradually from cusp across stylus to basis. All other elements occurred only in very small proportions. This altogether highlights that species can differ in their radular tooth chemistry which could potentially be used as tool for taxonomy [71].

For the central, lateral teeth I, marginal teeth, no gradients in iron, calcium, or any other inorganic components could be detected, thus these teeth are regarded as non-mineralized, similar to most gastropods and limpets [90, 91, 92].

By comparing treated and native radulae, we found that iron seems to be tightly bonded within Lepidochitona radular teeth, as it was not washed out by EDTA, whereas calcium and all slightly distributed elements do not seem to be tightly bonded. In the native specimens, reduction in the calcium proportion from row 25 on was detected. Potentially, under native conditions, calcium is washed out by surrounding fluids, either by passive diffusion or possibly by the salivary fluids. However, this awaits further investigations.

\section{Young's modulus and hardness}

Biological materials are generally composites displaying material heterogeneities or property gradients, which are important for the function of particular structure due to improved load bearing capacity or contact damage resistance [for comprehensive reviews, see 93, 94]. Functional material gradients have been investigated in numerous biological structures, such as e.g. Nereis jaws [95], crustacean exoskeleton [96, 97], pangolin scales [98, 99], wood stems [100, $101,102]$, and chiton and gastropod radular teeth $[18,24,30,57]$. Analyses of the material properties and their distribution complement morphology and enable the assignment of functions. The parameter Young's modulus (E) indicates the stiffness of a solid material and describes the relationship between tensile stress and axial strain. It correlates with the ability of the material (and structure) to transmit force [e.g. 103, 104, 105, 106], which is important to understand the puncturing behaviour and failure resistance [e.g. 107, for review on puncture mechanics, see 108]. The hardness $(\mathrm{H})$ is the measure of the resistance to local plastic deformation induced by indentation or abrasion.

In molluscs, the ontogenetic change in these parameters ( $\mathrm{E}$ and $\mathrm{H}$ ) was well investigated for the dominant teeth of Patella (Gastropoda). Here, the hardness increases dramatically from row 60 to 110 ( 150 rows in total) [45, 46]. For Lepidochitona, we observed a rather gradual increase in hardness and elasticity modulus for most tooth parts. Only in the styli of the lateral teeth II, their $\mathrm{E}$ and $\mathrm{H}$ values increased rather exponentially from row 15 to row 22.

Overall, hardness and elasticity values vary between studies and molluscan taxa. [20] analysed the mature dominant lateral tooth regions by nanoindentation in Cryptochiton and revealed that the leading edge has a hardness of 10.2-10.4 GPa and a Young's modulus of 128.5-130.8 GPa, the trailing edge - $\mathrm{H}=7.5-$ 8.2 $\mathrm{GPa}$ and $\mathrm{E}=97.6-114.8 \mathrm{GPa}$, and the core $-\mathrm{H}=1.5-1.6 \mathrm{GPa}$ and $\mathrm{E}=28.6-29.4 \mathrm{GPa}$. [109] determined $\mathrm{H}=3.6 \mathrm{GPa}$ and $\mathrm{E}=86 \mathrm{GPa}$ for the core, comparable to vertebrate enamel [110]. For mature limpet tooth cusps (Gastropoda), E=16 GPa in dry state and E=8 GPa in wet state was measured by nanoindentation for Megathura [23]. However, for Patella cusps, $\mathrm{E}=120$ (up to $\mathrm{E}=140 \mathrm{GPa}$ ) and $\mathrm{H}=4.9 \mathrm{GPa}$ was reported [19, 21]. For paludomid gastropods, $\mathrm{E}=8 \mathrm{GPa}$ and $\mathrm{H}=0.4$ GPa were measured for the tooth cusps [24, 27, 30]. For the stylus of polyplacophoran teeth, $\mathrm{H}=0.2-1.8 \mathrm{GPa}$ and $\mathrm{E}=7-30 \mathrm{GPa}$ [109] or from $\mathrm{E}=18 \mathrm{GPa}$ (for upper stylus) to $\mathrm{E}=12 \mathrm{GPa}$ (basis) [111] were previously determined. Here the walls of the stylus canal and the core of the upper stylus are rather soft and flexible, whereas the outer parts are stiffer and harder [109, 111]. [112] identified a hardness of $0.6 \mathrm{GPa}$ and a Young's modulus of $10.5 \mathrm{GPa}$ for the stylus leading edge. The stylus becomes first softer (hardness: $0.55 \mathrm{GPa}$, Young's modulus: $9.5 \mathrm{GPa}$ ) and then again harder and stiffer (hardness: $0.60-0.65 \mathrm{GPa}$,

Page $13 / 30$ 
Young's modulus: 11-12 GPa) towards the stylus canal. The stylus is both the hardest and stiffest at its outer layer of the trailing edge (hardness: $0.6-0.7$ GPa, Young's modulus: 12-14 GPa); both parameters decrease around the stylus canal (hardness: $0.55 \mathrm{GPa}$, Young's modulus: 11 GPa) [112].

For Lepidochitona, we detected graded values of hardness and Young's modulus for every individual tooth type, which is in congruence with the previous studies on Polyplacophora, but also with analyses of radular teeth from paludomid gastropod species that forage on algae attached to rocks [24, 27, 30]. The cusps were always the stiffest and hardest elements, followed by the stylus, and finally the basis. This probably enables the cusps to puncture or interact with the ingesta with possible formation of local stress. The tooth styli and bases enable the avoidance of structural failure or heavy abrasive wear, as it had been observed for paludomid gastropods [24, 27, 30]. Due to the smallness of the analyzed structures we were not able to differentiate between the core and the cusp edges in Lepidochitona, but values of the mature cusps of the dominant lateral teeth are comparable to cores of Cryptochiton [20] and the values of the styli are comparable to the values detected in other polyplacophorans $[109,111,112]$. The hardness and elasticity moduli of the central, lateral teeth I, and marginal teeth are comparable to the values detected for the limpet Megathura [23].

\section{Breaking force and stress}

For proper functioning, failures of biological structures must be avoided or reduced and studies on various biological structures, as e.g. insect wings and their components $[113,114,115,116,117,118,119,120]$, mammal teeth $[121,122,123,124,125,126,127,128,129]$, or bones [130, 131, 132, 133, 134, 135, 136, 137], depict the multiple origins of failure prevention. As biological structures are adapted to certain functional loads, the analysis of forces leading to the structural failure could lead to the detection of e.g. functional specialisations.

For radulae, mechanisms contributing to the avoidance of structural failure were already in focus of research [e.g. 26, 36, 37, 138, 139]. A proper stress distribution, reducing high local stress, is probably enabled by the inner structure of the tooth, i.e. fibre orientation [49, 139], and the radular membrane itself [3, $26,139,140]$, as the wet membrane enables a higher bending capability of the tooth $[26,28]$.

Teeth also contribute to the prevention of failure by their mechanical behaviour, which is based on their individual morphology, arrangement in particular arrays, mechanical properties, and water content. Tooth morphology can enable the tooth to rely on adjacent teeth of the adjacent rows or to bend and slip away leading to the resistance of higher forces, which were previously termed 'collective effect' $[26,28]$. The strong ability to bend, enabling a higher range of motion for tooth cusps, including the ability to deform and twist, when shear force is applied, was observed for long, slender, and thin teeth of paludomid gastropods [25, 26, 28,35] and is also observed for the marginals, lateral teeth I, and centrals of Lepidochitona. However, this capability is only possible, when teeth are loaded under wet condition. In dry condition, the thin teeth break at their bases or stylus. The wet lateral teeth II of Lepidochitona are also capable of bending [see also 109]; here the basis and stylus bend in contrast to the stiff and hard iron-containing cusp, leading to structural failure underneath the junction zone. The lateral teeth II are in Lepidochitona the only teeth that are capable of relying on the stylus of the adjacent lateral tooth II, resulting in the resistance to high forces. This ability is, however, not as pronounced as in paludomid gastropods [26, 28]. Under dry condition, lateral teeth II are not capable of bending and break, when loaded, directly at the junction zone.

A stiffer part (higher E) of the tooth rather transfers forces, when e.g. interacting with the ingesta, whereas more flexible regions (lower E) enable the structure to bend. Previous breaking stress experiments in paludomid gastropods revealed that tooth failure usually occurred at the softest and most flexible part of the tooth (stylus and basis), whereas the hardest and stiffest parts (cusps) are not as prone to failure under applied shear force. The same pattern is also observed for Lepidochitona as teeth usually break at their soft and flexible parts.

The hardness and stiffness of wet biological materials are lower than those of dry ones. Additionally, dry materials have lower fracture toughness [e.g. 114, $115,141,142,143,144,145,146,147,148]$. This was also previously reported for chiton radular teeth with wet teeth having $15 \%$ reduction in Young's modulus and hardness [18]. However, previous breaking stress experiments on teeth of paludomid gastropods showed that wet teeth are capable of resisting higher stresses than dry ones due to the increased flexibility of teeth and membrane $[26,28]$. This distributes the stress from the tooth cusps to the radular membrane $[3,14,22,32,33,34,112,149]$. The same pattern was observed in Lepidochitona, as wet radular structures were capable of resisting higher stresses than the dry ones.

Lepidochitona teeth were capable of resisting higher forces than teeth of paludomid gastropods [26, 28]. Here the wet and mature central teeth of the species, foraging on algae attached to stone, showed the highest degree of collective effect, allowing the teeth to resist $754 \pm 406.62 \mathrm{mN}$. The wet and mature lateral teeth II of Lepidochitona resisted to $1150 \pm 143 \mathrm{mN}$, whereas the wet and mature marginals, centrals, and lateral teeth I resisted to much lower forces (Ct: 379 $\pm 75 \mathrm{mN}$; Lt I $360 \pm 134 \mathrm{mN}$; Mt: $94 \pm 18 \mathrm{mN}$ ). These latter values are rather comparable to the breaking forces of wet and mature teeth of paludomid species foraging on mixed feeding substrate (plant surface, sandy surfaces, and occasionally on rocky surfaces) [28]. We would, thus, assume that centrals, lateral teeth I, and marginals of Lepidochitona are capable of occasional, but not regular interaction with the solid feeding substrate (rock).

\section{Origins of the mechanical property gradients and the behaviour}

In biological materials, functional gradients and heterogeneities can have their origin in geometry, chemistry, and/or structure [for review on the origins of gradients and heterogeneities see 93]. E.g. in abalone shells gradients are induced by the arrangement of structures [150, 151, 152], in the cephalopod sucker ring by their distribution $[153,154]$, in crustacean exoskeletons by their dimensions [96, 97, 155], in pangolin scales by their orientation [98, 99], in tarsal setae of ladybird beetle gradients are induced by the distribution of the protein resilin and different degree of sclerotization [156, 157], in squid's beak by a combination of the regionalization of histidine-rich proteins and the degree of hydration [158, 159, 160], in mammal teeth or bones by multiple gradient types $[161,162,163,164,165,166,167]$, and in the dominant lateral teeth of chitons and limpets by the distribution of the inorganic components and the architecture of the organic components $[18,20,57,109,111,112,168]$.

The here detected values of $\mathrm{E}$ and $\mathrm{H}$ in the dominant lateral teeth (lateral teeth II) of Lepidochitona highly correlate to the iron and the calcium proportions. The relationship between hardness and iron content was previously described for limpet teeth [21, 45, 46, 47] and for chiton teeth [18, 20, 57, 112], but here for

Page $14 / 30$ 
Lepidochitona we are now able to determine correlation coefficients. Additionally we assume that organic components and degree of tanning have a high influence on the mechanical properties as well. Thus, the property gradients of the lateral teeth II probably have their origin in the combination of iron, calcium, and organic substances, as it had been described for Cryptochiton teeth [20,57, 111]. In limpets, hardness seems to depend additionally on silicon content [45, $46,47]$, but in Lepidochitona only small proportions of silicon were detected.

For the centrals, lateral teeth I, and marginal teeth, we detected smaller correlation coefficients between hardness, Young's modulus, and the amount of calcium ( $r=0.23-0.32)$ and no correlations between hardness, Young's modulus, and the amount of iron. Thus, the measured gradients in $\mathrm{H}$ and $\mathrm{E}$ and the resulting mechanical behaviour of the teeth of Lepidochitona could be rather based on the radular organic components, as distinct folding or bounding conditions of the chitin due to tanning [5], a mixture of both, or/and fibre size, arrangement, distribution, and/or density [19, 20, 23, 68, 78, 109, 168, 169, 170]. As the fibre orientation contributes highly to the mechanical behaviour of teeth and to the self-sharpening effect $[47,168,170,171,172]$, this should be investigated for Lepidochitona in the future.

For Lepidochitona, we demonstrated relationship between the breaking force of the central teeth (and the lateral teeth II) and the mean iron and the mean calcium contents. The breaking force of the lateral teeth I strongly correlates with the mean calcium content and less strong with mean iron content. The breaking force of the marginal teeth strongly correlates with the mean calcium content. For the breaking stress similar patterns were observed. Thus, calcium content seems to have a high influence on the biomechanics of all teeth. In breaking stress experiments, we observed that wet and treated radulae resisted to higher forces. This indicates that the degree of mineralization with calcium hinders the tooth from bending, but the reduction of this element enables a higher collective effect under wet conditions. A very high bending amplitude had also been detected for the unmineralized teeth of paludomid gastropods [26, 28].

\section{Function of radular structures}

During foraging, a rotatory scraping action of the dominant lateral teeth, followed by inward sweeping action, enabled by the bending of the radula, can be observed in chitons $(2,31,111,173,174]$. For this purpose, the membrane must be flexible and capable of changing its shape, but it must also be strong and tough, to avoid failure during this action [see 44,111]. This is in congruence with our results from the breaking stress experiments in Lepidochitona and paludomid gastropods $[26,28]$, where we observed that the wet membrane is flexible enough to enable the bending of embedded teeth and additionally contributes to stress distribution. The dominant lateral tooth cusps possess caps of exceptional hardness, reducing wear and contributing to a self-sharpening effect [18, 20, 48, 170, 172; see also 168 for limpets]. This, together with their high ability to resist forces (documented here) and with the previously documented foraging behaviour and observed rotating interaction of the dominant lateral teeth with the ingesta surface [2,31, 147], depicts that these teeth loosen the food from the hard surface and transport them towards the mouth $[44,111]$. The underlain softer core of the tooth seems to serve as a shock absorption and toughening mechanism [170], as it was observed in other biological materials [e.g. 175, 176, 177, 178].

It was previously reported that due to the specific shape of the cusp and the gradients in hardness and Young's modulus across the tooth, tensile stress is concentrated on the leading edge and reduced in the trailing edge, reducing the ability of the tooth to bend and thus reduce the failure of the sharp tip of the tooth $[20,48]$. It was also reported that the stylus enables the sweeping action during feeding [109, 111], orients the tooth to the ingesta [48], but also transfers force from the basis to the tooth cusp [112] leading to the reduction of structural failure [111]. These mechanical behaviours, which are based on the graded mechanical property gradients, were also confirmed by breaking stress experiments in Lepidochitona.

The centrals of Lepidochitona can resist highest forces, followed by lateral teeth I, and finally marginals, even though marginal teeth have (slightly) higher $\mathrm{E}$ and $\mathrm{H}$ values than lateral teeth I and marginals. This leads to the conclusion, that centrals potentially interact more frequently with the ingesta surface, followed by the lateral teeth I. Since the marginals can resist to significantly lesser forces, these teeth may be potentially responsible for collecting the loosened particles in the sweeping motion. We also detected material property gradients in every type of teeth, with the cusps always the hardest and stiffest tooth parts, followed by the styli, and finally the bases. This may lead to the conclusion that the cusps of these teeth probably also interact, or even puncture, the ingesta with the possible formation of local stress at the cusps, whereas the softer and flexible tooth styli and bases allow the avoidance of structural failure or heavy tooth wear during scratching on the hard substrate.

\section{Conclusion}

We here provide comprehensive data on the mechanical properties (hardness, elasticity) of all radular teeth from the chiton Lepidochitona cinerea. By employing energy-dispersive X-ray spectroscopy we could analyse the radular tooth chemistry and correlate the proportions of calcium and iron to the mechanical properties. We also tested the mechanical behaviour of the teeth in dry and wet condition, which altogether allowed conclusions about tooth function. Knowledge about the relationship of all parameters mentioned contributes to our understanding on the origins of mechanical property gradients and the processes reducing structural failure in radular teeth.

\section{Methods}

\section{Specimen studied and dissection}

Adult individuals were collected at the coast of the North Sea, at Husum in Germany, in summer 2019, shortly boiled, and preserved in $70 \%$ ethanol. They were identified as Lepidochitona cinerea (Linnaeus, 1767) [Polyplacophora: Chitonida: Ischnochitonidae] by employing the relevant literature [179]. The nomenclature and systematic position were checked using molluscabase.org, specimens were inventoried (collection number: ZMH 154653) in the malacological collection of the Zoologisches Museum Hamburg (ZMH), Germany, which is part of the Leibniz-Institute zur Analyse des Biodiversitätswandels (LIB). 
Overall, 20 adult specimens were used for this study. To receive the radula from the body, each specimen was placed on its dorsal side, a paramedian cut was performed on the ventral side of the head and the radula was carefully extracted by tweezers. Radulae were then manually freed from surrounding tissue always grabbing the radula by the alary processus to avoid tooth and membrane fractures.

\section{Treatment}

To test the influence of calcium, silicon, etc. on the mechanical properties, such as hardness, elasticity (Young's modulus), and breaking stress, 10 radulae were treated for seven days with ethylenediaminetetraacetic acid (EDTA). We followed the protocol of [180], using ethylene diamine tetra acetic acid disodium salt dehydrate (Carl Roth $\mathrm{GmbH}+$ Co. KG, Karlsruhe, Germany). EDTA is known for binding ions of e.g. magnesium and calcium and is thus used for e.g. decalcification of bones in histology. Radulae were washed with distilled water afterwards.

\section{Scanning electron microscopy (SEM) and light microscopy}

Scanning electron microscopy (SEM) images of the working zone (Figure 1a) and habitus images (Figure 1d) were taken from literature [174], since they studied specimens from the same lot. The teeth were categorized into different tooth types according to their morphology and arrangement on the radula (central tooth, lateral tooth I, lateral tooth II [ = dominant lateral tooth], and marginal tooth). On both lateral tooth II and marginal tooth, three distinct regions (cusp, stylus, and basis) and for the smaller lateral tooth I and central tooth two regions were defined (cusp and stylus).

For light microscopic imaging, six radulae (three native, see Figures $1 \mathrm{~g}$ and $3 \mathrm{a}$, and three treated ones, $=$ treated with EDTA, see Figures $1 \mathrm{~h}$ and $4 \mathrm{a}$ ) were cleaned in an ultrasonic bath for a few seconds, placed on a glass object slide, and left to dry under room conditions. Images were taken with magnifications between x50 and x700, employing the Keyence Digital Microscope VHX-7000 (KEYENCE, Neu-Isenburg, Germany) equipped with automatic stacking software. To achieve the highest possible resolution, radulae were documented in parts and later merged using Adobe Photoshop CS6 (Adobe Inc., San José, USA). Additionally, detailed images in specific depths of the lateral teeth were taken employing the optical microscope Leica DM2500 LED (Leica Camera AG, Wetzlar, Germany) to illustrate the irregularity and shift in tooth colour. Based on the general tooth colour and the presence of overlying epithelia, the tooth rows were either assigned to the radular sack (with overlain epithelia, cusps rather lighter), the mineralization zone (with overlain epithelia, cusps are rather darker due to more iron incrustations), or the working zone (without overlain epithelia).

\section{Elemental analysis and nanoindentation}

Six radulae (three of native and three of treated condition) were arranged on glass object slides (Carl Roth, Karlsruhe, Germany) by double-sided adhesive tape along their longitudinal axis so that the marginal teeth of one side were directly attached to the bottom. The adjacent lateral teeth II were thus located above, followed by the lateral teeth I, central teeth, again lateral teeth I, lateral teeth II, and finally, on top, the marginal teeth from the other side. Each radula was then dried under ambient temperature for three days and afterwards surrounded by a small, metallic ring which ensured an almost parallel sample surface. Epoxy resin (RECKLIEPOXIWST, RECKLI GmbH, Herne, Germany) was filled into the metallic ring and left polymerizing at room temperature for three days (Young's modulus of the polymerized epoxy is $1.2 \pm 0.3 \mathrm{GPa}$, modulus received from testing five localities per sample). This specific epoxy was chosen since it does not infiltrate the teeth. Object slide and tape were removed and, to receive longitudinal sections of each tooth, the embedded radulae were polished until the marginal teeth were on display (controlled by examining the samples by microscope) using sandpapers of different roughness. Then samples were smoothed with aluminium oxide polishing powder suspension of $0.3 \mu \mathrm{m}$ grainsize (PRESI GmbH, Hagen, Germany) on a polishing machine (Minitech 233/333, PRESI $\mathrm{GmbH}$, Hagen, Germany).

After polishing, the samples were cleaned from the polishing powder by an ultrasonic bath lasting five minutes. Samples (Figures $1 \mathrm{~b}, 2 \mathrm{a}, \mathrm{b})$ were then sputtercoated with platinum ( $5 \mathrm{~nm}$ layer). The elemental composition of specific areas of the embedded teeth was examined employing the SEM Zeiss LEO 1525 (One Zeiss Drive, Thornwood, New York, USA) equipped with an Octane Silicon Drift Detector (SDD) (micro analyses system TEAM, EDAX Inc., New Jersey, USA), always using an acceleration voltage of $20 \mathrm{kV}$ and the same settings (e.g. lens opening, working distance, etc.). Before analyses, the detector was always calibrated with copper. We performed elemental mappings for test purposes for Fe (iron), O (oxygen), Ca (calcium), Mg (magnesium), P (phosphor), Si (silicon), S (sulphur), Cl (chlorine), K (potassium), F (fluorine), Na (sodium) (Figures 1c, e, f), but for elements, rather present with lower proportions, this method is not sensitive enough (see e.g. calcium in Figure 1f). We thus decided to focus here on elemental analyses of small areas (10-15 $\left.\mu m^{2}\right)$ (Figure 2 ).

Overall, 4144 EDX measurements (for native radulae: 2074 and for treated radulae: 2070) were successfully performed. For each central and lateral tooth I, the two previously defined regions (stylus and cusp) and for each lateral tooth II and marginal tooth, the three areas (basis, stylus, and cusp) were investigated (Figures 1b, 2a, 2b). The proportion of the elements $\mathrm{H}$ (hydrogen), C (carbon), N (nitrogen), O, Pt (platinum), Al (aluminium), Ca, Na, Mg, Si, P, S, Cl, K, C, and Fe were detected and measured. We used the data of atomic ratio (atomic \%) for this study. The values were received with two positions after the decimal point: lower proportions were not detectable with this method and given as 0.00 . We did not analyse and discuss the following elements, as they are either the elemental basis of chitin ( $\mathrm{H}, \mathrm{C}, \mathrm{N}, \mathrm{O})$, the coating (Pt), or of the polishing powder ( $\mathrm{Al}, \mathrm{O})$. For some analyses or graphic depictions $\mathrm{Na}$, Mg, $\mathrm{Si}$, $\mathrm{P}, \mathrm{S}, \mathrm{Cl}, \mathrm{K}, \mathrm{Ca}$, and Fe were summed to 'all elements (Ae)' and $\mathrm{Na}, \mathrm{Mg}, \mathrm{Si}, \mathrm{P}, \mathrm{S}, \mathrm{Cl}$, and $\mathrm{K}$, as they were only sparsely detected, were summed to 'slightly distributed elements (Se)'.

After EDX analysis the same samples were used for nanoindentation [for the detailed nanoindentation protocol see 24, 27, 30]. Here, hardness (H) and Young's modulus (E, elastic modulus) of the regions, that were previously analysed by EDX, were identified. A nanoindenter SA2 (MTS Nano Instrument, Oak Ridge, Tennessee, USA) equipped with a Berkovich indenter tip and a dynamic contact module (DCM) head, allowing to test materials with low contact stiffness as soft biological tissues, was employed. Hardness and the effective elastic modulus could be determined from force-distance curves by applying the continuous stiffness measurement technique [181]. All tests were performed under normal room conditions (relative humidity $28-30 \%$, temperature $22-24^{\circ} \mathrm{C}$ ). Each indent and its curve were manually controlled. $\mathrm{E}$ and $\mathrm{H}$ of the material was either determined at penetration depth of $600-700 \mathrm{~nm}$ (for lateral tooth II), or at 500-600 nm (for all other teeth), with about 30 values per indentation, which were collated to receive one $\mathrm{H}$ and one $\mathrm{E}$ mean value per indent. After this, each sample was again polished and smoothened until the next tooth type was on display. Then cleaning, EDX analyses, and nanoindentation were again 
performed. These steps were repeated until all teeth were measured. Overall, we received successfully data on $\mathrm{E}$ and $\mathrm{H}$ for 4139 tooth areas (for native radulae: 2072 and for treated radulae: 2067$)$.

\section{Breaking force and breaking stress}

For breaking force experiments overall eight radulae were used (four of native and four of treated condition). For testing in dry condition, we used two native and two treated radulae, and for testing under wet condition, we also used two native and two treated radulae. As described in detail in Krings et al., (2021a, 2021c), each radula was mounted on one microscope glass slide (Carl Roth, Karlsruhe, Germany) either with double sided adhesive tape (for experiments in dry condition) or by applying epoxy (RECKLIEPOXIWST, RECKLI GmbH, Herne, Germany) to both alary processus and both sides of the radular membrane (for experiments in wet condition). As mentioned above, this epoxy was chosen, because it does not infiltrate the teeth. Then teeth were carefully stroked into proposed feeding position. For experiment in dry condition the mounted radulae were left to dry for four hours at room temperature. For experiments in wet condition the epoxy was left for two days to polymerize; afterwards radulae were rehydrated by applying distilled water onto the radula. Water drops on teeth were removed by soaking it up with tissues before experiment.

Glass slides with the radulae were positioned under binocular microscope and a rounded steel needle (diameter: $0.4 \mathrm{~mm}$ ), firmly attached to a force transducer FORT-1000 (World Precision Instruments, Sarasota, FL, USA), which was connected to an amplifier (Biopac System Inc., California, USA) and computer-based data acquisition and processing system (Acq Knowledge, Biopac Systems, Inc., version: 3.7.0.0, World Precision Instruments, Sarasota, Florida, USA), was pressed onto the individual tooth cusps by employing a remote-controlled micromanipulator (DC 3001R, World Precision Instruments Inc., Sarasota, Florida, USA). The needle was positioned on the concave part of each tooth cusps at $30^{\circ}$ to the horizontal plane and moved onto the cusps until structural failure occurred. The forces needed to either crush or shear teeth were recorded and their maxima were calculated from the obtained force-time diagrams. Overall, we received data from 1301 individual breaking force curves (equals the quantity of broken teeth). Afterwards the broken radulae were documented with the Tabletop scanning electron microscope TM4000 Plus (Hitachi, Tokyo, Japan) and the types (e.g. crushing, rupture, breaking, etc.) and region of the structural failure (basis, stylus, cusps, etc.) were examined (Figures 6a, b). Since the centrals and the lateral teeth I were either crushed or ripped, we were not able to measure their area of failure and to determine the breaking stress (breaking force divided by tooth cross sectional area). The lateral teeth II and the marginal teeth exhibited a rather plain breaking area, which could be measured. Here, the average breaking area was determined by documenting ten areas per tooth type and per radula using SEM. The obtained SEM images were imported into Adobe Illustrator CS 6 (Adobe Inc., San José, USA), here the breaking areas were outlined, and each outline was translated into an individual red area. By using the scale bar from SEM as reference a blue square area (in $\mu \mathrm{m}^{2}$ ) was also computed for each image. Then images were individually imported into Adobe Photoshop CS6 (Adobe Inc., San José, USA), here the quantity of blue and red pixels was read out. By accounting pixel quantity of the square with the pixel quantities for each broken tooth area, the area (in $\mu \mathrm{m}^{2}$ ) of failure and subsequently an average breaking area for each tooth type could be determined. Then breaking stress was calculated from the breaking force and the mean broken area for the corresponding tooth type.

\section{Statistical analyses}

All statistical analyses were performed with JMP Pro, Version 14 (SAS Institute Inc., Cary, North Caroline, 1989-2007). Mean values and standard deviations were calculated and Shapiro-Wilk-W-tests for testing of normality were conducted. When data was non-normal distributed, a Kruskal-Wallis test was carried out. When the data was normal distributed, either a t-test or ANOVA was performed to detect differences. Pairwise comparisons were conducted with Wilcoxon method (non-normal distribution) or Tukey-Kramer test (normal distribution). All correlations and 4-way ANOVA were also performed with JMP; relationships between parameters were here visualized. Gain or loss of E, H, Fe, Ca, Ae, Se from one row to the adjacent was calculated (e.g., Ca \% of tooth row 2 - Ca \% of tooth row 1 = gain or loss of Ca from row 1 to row 2). We set the highest proportion of e.g. Ca in whole radula to $100 \%$ to receive gain or loss of Ca in \%. A PCA based on results from elemental analysis and mechanical tests was conducted for all teeth (without lateral teeth II), to detect potential similarities between native centrals, native lateral teeth I, native marginals, treated centrals, treated lateral teeth I, and treated marginals.

\section{Declarations}

Consent for publication. All authors approved the final version of the manuscript for publication.

Availability of data and materials. All data is included in the supplementary file.

Competing interests. The authors declare no competing interest.

Funding. This research did not receive any specific grant from funding agencies in the public, commercial, or not-for-profit sectors.

Authors' contributions. WK and SG together initiated the project, designed the study, and discussed the data. In the course of his master thesis JOB performed EDX and light microscopy analyses of one specimen and collated the literature. WK together with JOB wrote the first draft of the manuscript. WK executed the remaining EDX analyses, the nanoindentation, and performed the statistical analyses. 
Acknowledgements. We would like to thank Renate Walter from the Zoological Institute, Universität Hamburg, for her great support with the SEM and the EDX analyses, the members of the Department of Functional Morphology and Biomechanics, Christian-Albrechts-Universität zu Kiel, for collecting specimens at Husum during the annual work outing, Thomas M. Kaiser from the CeNak, Universität Hamburg, for some discussion on the results, Peter Stutz from the Mineralogical-Petrographic Institute, Universität Hamburg, for his support with the nanoindentation and EDX sample preparation, Marco T. Neiber from the CeNak, Universität Hamburg, for species identification, and Frederick Jessen, from the CeNak, Universität Hamburg, for support with the light microscopy. We thank Frank Friedrich from the Zoological Institute, Universität Hamburg, for his supervision of the master thesis (that served as basis for this paper) of JOB, and his advices on the EDX data interpretation. We are also grateful for the technical support of Esther Appel and Alexander Kovalev from the Department of Functional Morphology and Biomechanics, Christian-Albrechts-Universität zu Kiel, at the beginning of the study. Finally, we thank anonymous reviewers for their helpful comments on the manuscript.

\section{References}

1. Chapman AD. Numbers of living species in Australia and the world. Toowoomba: Australian Biodiversity Information Services; 2009.

2. Guralnick R, Smith K. Historical and biomechanical analysis of integration and dissociation in molluscan feeding, with special emphasis on the true limpets (Patellogastropoda: Gastropoda). J Morphol. 1999;241(2):175-95.

3. Krings W, Brütt J-O, Gorb SN, Glaubrecht M. Tightening it up: Diversity of the chitin anchorage of radular-teeth in paludomid freshwater-gastropods. Malacologia. 2020;63(1):77-94.

4. Runham NW. Rate of replacement of the molluscan radula. Nature. 1962;194(4832):992-3.

5. Runham NW. A study of the replacement mechanism of the pulmonate radula. J Cell Sci. 1963;3(66):271-7.

6. Isarankura K, Runham N. Studies on the replacement of the gastropod radula. Malacologia. 1968;7(1):71-91.

7. Mackenstedt U, Märkel K. Experimental and comparative morphology of radula renewal in pulmonates (Mollusca, Gastropoda). Zoomorphology. 1987;107(4):209-39.

8. Eernisse DJ, Kerth K. The initial stages of radular development in chitons (Mollusca: Polyplacophora). Malacologia. 1988;28(1-2):95-103.

9. Lowenstam HA, Weiner S. Mollusca. In: Lowenstam HA, Weiner S, editors. On Biomineralization. Oxford: Oxford University Press; 1989. pp. 88-305.

10. Franz CJ. Feeding patterns of Fissurella species on Isla de Margarita, Venezuela: Use of radulae and food passage rates. J Molluscan Stud. 1990;56(1):25-35.

11. Padilla DK, Dittman DE, Franz J, Sladek R. Radular production rates in two species of Lacuna Turton (Gastropoda: Littorinidae). J Molluscan Stud. 1996;62(3):275-80.

12. Shaw JA, Macey DJ, Brooker LR. Radula synthesis by three species of iron mineralizing molluscs: Production rate and elemental demand. J Mar Biolog Assoc UK. 2008;88(3):597-601.

13. Saunders M, Kong C, Shaw JA, Clode PL. Matrix-mediated biomineralization in marine mollusks: A combined transmission electron microscopy and focused ion beam approach. Microsc Microanal. 2011;17:220-5.

14. Solem A. Malacological applications of scanning electron microscopy II. Radular structure and functioning. Veliger. 1972;14:327-36.

15. Steneck RS, Watling L. Feeding capabilities and limitation of herbivorous molluscs: A functional group approach. Mar Biol. 1982;68(3):299-319.

16. Breure ASH, Gittenberger E. The rock-scraping radula, a striking case of convergence (Mollusca). Neth J Zool. 1981;32(3):307-12.

17. Hawkins SJ, Watson DC, Hill AS, Harding SP, Kyriakides MA, Hutchinson S, Norton TA. A comparison of feeding mechanisms in microphagous, herbivorous, intertidal, prosobranchs in relation to resource partitioning. J Molluscan Stud. 1989;55(2):151-65.

18. Weaver JC, Wang Q, Miserez A, Tantuccio A, Stromberg R, Bozhilov KN, Maxwell P, Nay R, Heier ST, DiMasi E. Analysis of an ultra hard magnetic biomineral in chiton radular teeth. Mater Today. 2010;13(1-2):42-52.

19. Lu D, Barber AH. Optimized nanoscale composite behaviour in limpet teeth. J Royal Soc Interface. 2012;9(71):1318-24.

20. Grunenfelder LK, de Obaldia EE, Wang Q, Li D, Weden B, Salinas C, Wuhrer R, Zavattieri P, Kisailus D. Biomineralization: Stress and damage mitigation from oriented nanostructures within the radular teeth of Cryptochiton stelleri. Adv Funct Mater. 2014;24(39):6093-104.

21. Barber AH, Lu D, Pugno NM. Extreme strength observed in limpet teeth. J Royal Soc Interface. 2015;12(105):20141326.

22. Ukmar-Godec T, Kapun G, Zaslansky P, Faivre D. The giant keyhole limpet radular teeth: A naturally-grown harvest machine. J Struct Biol. 2015;192(3):392-402.

23. Ukmar-Godec T, Bertinetti L, Dunlop JWC, Godec A, Grabiger MA, Masic A, Nguyen H, Zlotnikov I, Zaslansky P, Faivre D. Materials nanoarchitecturing via cation-mediated protein assembly: Making limpet teeth without mineral. Adv Mater. 2017;29(27):1701171.

24. Krings W, Kovalev A, Glaubrecht M, Gorb SN. Differences in the Young modulus and hardness reflect different functions of teeth within the taenioglossan radula of gastropods. Zoology. 2019;137:125713.

25. Krings W, Marcé-Nogué N, Karabacak H, Glaubrecht M, Gorb SN. Finite element analysis of individual taenioglossan radula teeth. Acta Biomater. 2020;115:317-32.

26. Krings W, Kovalev A, Gorb SN. Influence of water content on mechanical behaviour of gastropod taenioglossan radulae. Proc. Royal Soc. B 2021;288:1946.

27. Krings W, Neiber MT, Kovalev A, Gorb SN, Glaubrecht M. Trophic specialisation reflected by radular tooth material properties in an 'ancient' Lake Tanganyikan gastropod species flock. BMC Ecol Evo. 2021;21:35.

Page $18 / 30$ 
28. Krings W, Kovalev A, Gorb SN. Collective effect of damage prevention in taenioglossan radular teeth is related to the ecological niche in Paludomidae (Gastropoda: Cerithioidea). Acta Biomater. 2021;135:458-72.

29. Krings W. Trophic specialization of paludomid gastropods from 'ancient' Lake Tanganyika reflected by radular tooth morphologies and material properties. Dissertation, Universität Hamburg; 2020. https://ediss.sub.uni-hamburg.de/handle/ediss/8654.

30. Gorb SN, Krings W. Mechanical property gradients of taenioglossan radular teeth are associated with specific function and ecological niche in Paludomidae (Gastropoda: Mollusca). Acta Biomater. 2021;134:513-30.

31. Eigenbrodt H. Untersuchungen über die Funktion der Radula einiger Schnecken. Zeitschrift für Morphologie Ökologie der Tiere. 1941;37(4):735-91.

32. Hickman CS. Gastropod radulae and the assessment of form in evolutionary paleontology. Paleobiology. 1980;6(3):276-94.

33. Hickman CS. Implications of radular tooth-row functional integration for archaeogastropod systematics. Malacologia. 1984;25(1):143-60.

34. Padilla DK. Form and function of radular teeth of herbivorous molluscs: Focus on the future. Am Malacol Bull. 2003;18(1):163-8.

35. Krings W, Marcé-Nogué J, Gorb SN. Finite element analysis relating shape, material properties, and dimensions of taenioglossan radular teeth with trophic specialisations in Paludomidae (Gastropoda). Sci Rep. 2021;11:22775.

36. Krings W, Hempel C, Siemers L, Neiber MT, Gorb SN. Feeding experiments on Vittina turrita (Mollusca, Gastropoda, Neritidae) reveal tooth contact areas and bent radular shape during foraging. Sci Rep. 2021;11:9556.

37. Krings W, Gorb SN. Substrate roughness induced wear pattern in gastropod radulae. Biotribology. 2021;26:100164.

38. Krings W, Karabacak H, Gorb SN. From the knitting shop: The first physical and dynamic model of the taenioglossan radula (Mollusca: Gastropoda) aids in unravelling functional principles of the radular morphology. J R Soc Interface. 2021;1820210377:20210377.

39. Jones E, McCance R, Shackleton L. The role of iron and silica in the structure of the radular teeth of certain marine molluscs. J Exp Biol. 1935;12(1):5964.

40. Lee AP, Brooker LR, Macey DJ, Webb J, van Bronswijk W. A new biomineral identified in the cores of teeth from the chiton Plaxiphora albida. J Biol Inorg Chem. 2003;8(3):256-62.

41. Emmanuel S, Schuessler JA, Vinther J, Matthews A, von Blanckenburg F. A preliminary study of iron isotope fractionation in marine invertebrates (chitons, Mollusca) in near-shore environments. Biogeosciences. 2014;11(19):5493-502.

42. Brooker LR, Shaw JA. The chiton radula: A unique model for biomineralization studies. In: Seto J, editor. Advanced topics in biomineralization. Rijeka: Intech Open; 2012. pp. 65-84.

43. Faivre D, Ukmar-Godec T. From bacteria to mollusks: the principles underlying the biomineralization of iron oxide materials. Angew Chem Int Ed Engl. 2015;54(16):4728-47.

44. Joester D, Brooker LR. The chiton radula: A model system for versatile use of iron oxides. In: Faivre D, editor. Iron oxides: From nature to applications. Weinheim: Wiley-VCH; 2016. pp. 177-205.

45. Runham NW, Thronton PR, Shaw DA, Wayte RC. The mineralization and hardness of the radular teeth of the limpet Patella vulgata L. Z. Zellforsch. 1969;99:608-26.

46. Vincent JFV. The hardness of the tooth of Patella vulgata L. radula: A reappraisal. J Molluscan Stud. 1980;46:129-33.

47. van der Wal P. Structural and material design of mature mineralized radula teeth of Patella vulgata (Gastropoda). J Ultrastruct Mol Struct Res. 1989;102(2):147-61.

48. van der Wal P, Giesen HJ, Videler JJ. Radular teeth as models for the improvement of industrial cutting devices. Mater Sci Eng C. 1999;7(2):129-42.

49. Shaw JA, Macey DJ, Brooker LR, Clode PL. Tooth use and wear in three iron-biomineralizing mollusc species. Biol Bull. 2010;218(2):132-44.

50. Kakei M, Yoshikawa M, Mishima H. TEM study of the radular teeth of the chiton Acanthopleura japonica. In: Endo K, Kogure T, Nagasawa H, editors. Biomineralization. Singapore: Springer; 2018. pp. 11-20.

51. Macey DJ, Brooker LR. The junction zone: Initial site of mineralization in radula teeth of the chiton Cryptoplax striata (Mollusca: Polyplacophora). J Morphol. 1996;230:33-42.

52. Shaw JA, Macey DJ, Brooker LR, Stockdale EJ, Saunders M, Clode PL. The chiton stylus canal: An element delivery pathway for tooth cusp biomineralization. J Morphol. 2009;270:588-600.

53. Towe KM, Lowenstam HA. Ultrastructure and development of iron mineralization in the radular teeth of Cryptochiton stelleri (Mollusca). J Ultrastruct Res. 1967;17(1-2):1-13.

54. Kirschvink JL, Lowenstam HA. Mineralization and magnetization of chiton teeth: Paleomagnetic, sedimentalogic and biologic implications of organic magnetite. EPSL. 1979;44:193-204.

55. Kim KS, Macey DJ, Webb J, Mann S. Iron mineralisation in the radula teeth of the chiton Acanthopleura hirtosa. Proc. Royal Soc. B 1989;237:335-46.

56. Brooker LR, Lee AP, Macey DJ, van Bronswijk W, Webb J. Multiple-front iron-mineralisation in chiton teeth (Acanthopleura echinata: Mollusca: Polyplacophora). Mar. Biol. 2003;142:447-54.

57. Wang Q, Nemoto M, Li D, Weaver JC, Weden B, Stegemeier J, Bozhilov KN, Wood LR, Milliron GW, Kim CS, DiMasi E, Kisailus D. Phase transformations and structural developments in the radular teeth of Cryptochiton stelleri. Adv Funct Mater. 2013;23:2908-17.

58. Kisailus D, Nemoto M. Structural and proteomic analyses of iron oxide biomineralization in chiton teeth. In: Matsunaga T, Tanaka T, Kisailus D, editors.

Biological magnetic materials and applications. Singapore: Springer; 2018. pp. 53-73.

59. Moura HM, Unterlass MM. Biogenic metal oxides. Biomimetics. 2020;5(2):29.

Page $19 / 30$ 
60. Nemoto M, Wang Q, Li D, Pan S, Matsunaga T, Kisailus D. Proteomic analysis from the mineralized radular teeth of the giant Pacific chiton, Cryptochiton stelleri (Mollusca). Proteomics. 2012;12:2890-4.

61. Stockdale EJ, Shaw JA, Macey DJ, Clode PL. Imaging organic and mineral phases in a biomineral using novel contrast techniques. Scanning. 2009;31:11-8.

62. van der Wal P. Structure and formation of the magnetite-bearing cap of the polyplacophoran tricuspid radula teeth. In: Frankel RB, Blakemore RP, editors. Iron biominerals. New York: Plenum Press; 1990. pp. 221-9.

63. Lowenstam HA. Magnetite in denticle capping in recent chitons (Polyplacophora). Geol Soc Am Bull. 1962;73:435-8.

64. McCoey JM, Matsuoka M, de Gille RW, Hall LT, Shaw JA, Tetienne J-P, Kisailus D, Hollenberg LCL, Simpson DA. Quantum magnetic imaging of iron biomineralization in teeth of the chiton Acanthopleura hirtosa. Small Methods. 2020;4:1900754.

65. Han Y, Liu C, Zhou D, Li F, Wang Y, Han X. Magnetic and structural properties of magnetite in radular teeth of chiton Acanthochiton rubrolinestus. Bioelectromagnetics. 2011;32:226-33.

66. Nemoto M, Ren D, Herrera S, Pan S, Tamura T, Inagaki K, Kisailus D. Integrated transcriptomic and proteomic analyses of a molecular mechanism of radular teeth biomineralization in Cryptochiton stelleri. Sci Rep. 2019;9:856.

67. Lowenstam HA. Lepidocrocite, an apatite mineral, and magnetite in teeth of chitons (Polyplacophora). Science. 1967;56:1373-5.

68. Evans LA, Macey DJ, Webb J. Matrix heterogeneity in the radular teeth of the chiton Acanthopleura hirtosa. Acta Zool. 1994;75(1):75-9.

69. Lee AP, Webb J, Macey DJ, van Bronswijk W, Savarese AR, de Witt GC. In situ Raman spectroscopic studies of the teeth of the chiton Acanthopleura hirtosa. J Biol Inorg Chem. 1998;3:614-9.

70. Lee AP, Brooker LR, Macey DJ, van Bronswijk W, Webb J. Apatite mineralization in teeth of the chiton Acanthopleura echinata. Calcif Tissue Int. 2000;67:408-15.

71. Brooker LR, Macey DJ. Biomineralization in chiton teeth and its usefulness as a taxonomic character in the genus Acanthopleura Guilding, 1829 (Mollusca: Polyplacophora). Am Malacol Bull. 2001;16(1/2):203-15.

72. Brooker LR, Lee AP, Macey DJ, Webb J, van Bronswijk W. In situ studies of biomineral deposition in the radula teeth of chitons of the suborder Chitonina. Venus. 2006;65(1-2):71-80.

73. Saunders M, Kong C, Shaw JA, Macey DJ, Clode PL. Characterization of biominerals in the radula teeth of the chiton, Acanthopleura hirtosa. J Struct Biol. 2009;167:55-61.

74. Lee AP, Brooker LR, van Bronswijk W, Macey DJ, Webb J. Contribution of Raman spectroscopy to identification of biominerals present in teeth of Acanthopleura rehderi, Acanthopleura curtisiana, and Onithochiton quercinus. Biopolymers 2003;72:299-301.

75. Lowenstam HA, Weiner S. Transformation of amorphous calcium phosphate to crystalline dahllite in the radula teeth of chitons. Science. 1985;227:51-2.

76. Brooker LR, Lee AP, Macey DJ, Webb J. Molluscan and other marine teeth. In: Cahn RW, Calvert PD, editors. Encyclopedia of Materials: Science and Technology. Oxford: Elsevier Science Ltd.; 2001. pp. 5186-9.

77. Shaw JA, Macey DJ, Brooker LR, Stockdale EJ, Saunders M, Clode PL. Ultrastructure of the epithelial cells associated with tooth biomineralization in the chiton Acanthopleura hirtosa. Microsc. Microanal. 2009;15(2):154-65.

78. Gordon L, Joester D. Nanoscale chemical tomography of buried organic- inorganic interfaces in the chiton tooth. Nature. 2011;469:194-8.

79. Lowenstam HA. Phosphatic hard tissues of marine invertebrates, their nature and mechanical function, and some fossil implications. Chem Geol. 1972;9:153-66.

80. Macey DJ, Webb J, Brooker LR. The structure and synthesis of biominerals in chiton teeth. Bull Inst Océanogr (Monaco). 1994;4(1):191-7.

81. Irisarri I, Uribe JE, Eernisse DJ, Zardoya R. A mitogenomic phylogeny of chitons (Mollusca: Polyplacophora). BMC Evol Biol. 2020;20:22.

82. Kim KS, Webb J, Macey DJ. Properties and role of ferritin in the hemolymph of the chiton Clavarizona hirtosa. BBA. 1986;884:387-94.

83. Nesson MH, Lowenstam HA. Biomineralization processes of the radula teeth of chitons. In: Kirschvink JL, Jones DS, MacFadden BJ, editors. Magnetite biomineralization and magnetoreception in organisms. New York: Plenum Press; 1985. pp. 333-61.

84. Sone ED, Weiner S, Addadi L. Biomineralization of limpet teeth: A cryo-TEM study of the organic matrix and the onset of mineral deposition. J Struct Biol. 2007;158:428-44.

85. Kim KS, Webb J, Macey DJ, Cohen DD. Compositional changes during biomineralization of the radula of the chiton Clavarizona hirtosa. J Inorg Biochem. 1986;28(2-3):337-45.

86. Saunders M, Shaw JA, Clode PL, Kong C, Macey DJ. Fine-scale analysis of biomineralized mollusc teeth using FIB and TEM. MTO 2010;18(1):24-8.

87. Evans LA, Alvarez R. Characterization of the calcium biomineral in the radular teeth of Chiton pelliserpentis. J Biol Inorg Chem. 1999;4(2):166-70.

88. Evans LA, Macey DJ, Webb J. Calcium biomineralization in the radula teeth of the chiton, Acanthopleura hirtosa. Calcif Tissue Int. 1992;51:78-82.

89. Evans LA, Macey DJ, Webb J. Distribution and composition of the matrix protein in the radula teeth of the chiton Acanthopleura hirtosa. Mar Biol. 1991;109:281-86.

90. Haszprunar G. On the origin and evolution of major gastropod groups, with special reference to the Streptoneura. J Molluscan Stud. 1988;54:367-441.

91. Sasaki T. Comparative anatomy and phylogeny of the recent Archaeogastropoda (Mollusca: Gastropoda). Univ of Tokyo Bull. 1998;38:1-224.

92. Simone LRL. Phylogeny of the Caenogastropoda (Mollusca), based on comparative morphology. Arq Zool. 2011;42(4):161-323.

93. Liu ZQ, Meyers MA, Zhang ZF, Ritchie RO. Functional gradients and heterogeneities in biological materials: Design principles, functions, and bioinspired applications. Progr Mater Sci. 2017;88:467-98.

Page 20/30 
94. Huang W, Restrepo D, Jung J-Y, Su FY, Liu Z, Ritchie RO, McKittrick J, Zavattieri P, Kisailus D. Multiscale toughening mechanisms in biological materials and bioinspired designs. Adv Mater. 2019;31:1901561.

95. Broomell CC, Chase SF, Laue T, Waite JH. Cutting edge structural protein from the jaws of Nereis virens. Biomacromol. 2008;9:1669-77.

96. Raabe D, Sachs C, Romano P. The crustacean exoskeleton as an example of a structurally and mechanically graded biological nanocomposite material. Acta Mater. 2005;53:4281-92.

97. Chen P-Y, Lin AYM, McKittrick J, Meyers MA. Structure and mechanical properties of crab exoskeletons. Acta Biomat. 2008;4:587-96.

98. Liu ZQ, Jiao D, Weng ZY, Zhang ZF. Structure and mechanical behaviors of protective armored pangolin scales and effects of hydration and orientation. J Mech Behav Biomed Mater. 2016;56:165-74.

99. Wang B, Yang W, Sherman VR, Meyers MA. Pangolin armor: overlapping, structure, and mechanical properties of the keratinous scales. Acta Biomat. 2016;41:60-74.

100. Eder M, Jungnikl K, Burgert I. A close-up view of wood structure and properties across a growth ring of Norway spruce (Picea abies [L] Karst.). Trees. 2009;23:79-84.

101. Speck T, Burgert I. Plant stems: functional design and mechanics. Annu Rev Mater Res. 2011;41:169-93.

102. Gibson LJ. The hierarchical structure and mechanics of plant materials. J Royal Soc Interface. 2012;9:2749-66.

103. Bendsøe MP. Optimal shape design as a material distribution problem. Struct Optim. 1989;1:193-202.

104. Bendsøe MP. Optimization of structural topology, shape and material. Berlin: Springer; 1995.

105. Bendsøe MP, Kikuchi N. Generating optimal topologies in structural design using a homogenization method. Comput Methods Appl Mech Eng. 1988;71:197-224.

106. Dumont ER, Grosse IR, Slater GJ. Requirements for comparing the performance of finite element models of biological structures. J Theor Biol. 2009;256:96-103.

107. Freeman PW, Lemen CA. The trade-off between tooth strength and tooth penetration: Predicting optimal shape of canine teeth. J Zool. $2007 ; 273: 273-80$.

108. Anderson PSL. Making a point: Shared mechanics underlying the diversity of biological puncture. J Exp Biol. 2018;221:jeb187294.

109. Stegbauer L, Smeets PJM, Free R, Wallace SG, Hersam MC, Alp EE, Joester D. Persistent polyamorphism in the chiton tooth: From a new biomineral to inks for additive manufacturing. PNAS. 2021;118(23):e2020160118.

110. Zok FW, Miserez A. Property maps for abrasion resistance of materials. Acta Mater. 2007;55(18):6365-71.

111. Pohl A, Herrera SA, Restrepo D, Negishi R, Jung J-Y, Salinas C, Wuhrer R, Yoshino T, McKittrick J, Arakaki A, Nemoto M, Zavattieri P, Kisailus D. Radular stylus of Cryptochiton stelleri: A multifunctional lightweight and flexible fiber-reinforced composite. J Mech Behav Biomed Mater. 2020;111:103991.

112. Herrera SA, Grunenfelder L, Escobar E, Wang Q, Salinas C, Yaraghi N, Geiger J, Wuhrer R, Zavattieri P, Kisailus D. Stylus support structure and function of radular teeth in Cryptochiton stelleri. 20th International Conference on Composite Materials Copenhagen, 19-24th July, 2015.

113. Newman DJS, Wootton RJ. An approach to the mechanics of pleating in dragonfly wings. J Exp Biol. 1986;125:361-72.

114. Dirks J-H, Taylor D. Fracture toughness of locust cuticle. J Exp Biol. 2012;215:1502e1508.

115. Dirks J-H, Taylor D. Veins improve fracture toughness of insect wings. PLoS One. 2012;7:e43411.

116. Mountcastle AM, Combes SA. Biomechanical strategies for mitigating collision damage in insect wings: structural design versus embedded elastic materials. J Exp Biol. 2014;217:1108-15.

117. Appel E, Heepe L, Lin CP, Gorb SN. Ultrastructure of dragonfly wing veins: Composite structure of fibrous material supplemented by resilin. J Anat. 2015;227:561-82.

118. Rajabi H, Bazargan P, Pourbabaei A, Eshghi S, Darvizeh A, Gorb SN, Taylor D, Dirks J-H. Wing cross veins: An efficient biomechanical strategy to mitigate fatigue failure of insect cuticle. Biomech Model Mechan. 2017;16:1947-55.

119. Rajabi H, Shafiei A, Darvizeh A, Gorb SN. Resilin microjoints: a smart design strategy to avoid failure in dragonfly wings. Sci Rep. 2016;6:39039.

120. Rudolf J, Wang L-Y, Gorb SN, Rajabi H. On the fracture resistance of dragonfly wings. J Mech Behav Biomed Mater. 2019;99:127-33.

121. von Königswald W, Pfretzschner HU. Biomechanics in the enamel of mammalian teeth. In: Schmidt-Kittler N, Vogel K, editors. Constructional morphology and evolution. Berlin: Springer; 1991. pp. 113-25.

122. Lawn BR, Lee JJ-W, Constantino PJ, Lucas PW. Predicting failure in mammalian enamel. J Mech Behav Biomed. 2009;2:33-42.

123. Bechtle S, Özcoban H, Lilleodden ET, Huber N, Schreyer A, Swain MV, Schneider GA. Hierarchical flexural strength of enamel: Transition from brittle to damage-tolerant behaviour. J Royal Soc Interface. 2012;9:1265-74.

124. Schulz E, Calandra I, Kaiser TM. Feeding ecology and chewing mechanics in hoofed mammals: 3D tribology of enamel wear. Wear. 2013;300:169-79.

125. Yahyazadehfar M, Mutluay MM, Majd H, Ryou H, Arola D. Fatigue of the resin-enamel bonded interface and the mechanisms of failure. $J$ Mech Behav Biomed. 2013;21:121-32.

126. Yilmaz ED, Schneider GA, Swain MV. Influence of structural hierarchy on the fracture behaviour of tooth enamel. Philos Trans A Math Phys Eng Sci. 2015;28:373

127. Lucas PW, Philip SM, Al-Qeoud D, Al-Draihim N, Saji S, van Casteren A. Structure and scale of the mechanics of mammalian dental enamel viewed from an evolutionary perspective. Evol Dev. 2016;18:54-61.

128. Wilmers J, Bargmann S. Nature's design solutions in dental enamel: uniting high strength and extreme damage resistance. Acta Biomater. 2020;107:1-24. 
129. Pro JW, Barthelat F. Discrete element models of fracture in tooth enamel: failure mode competition and statistical effects. J Mech Phys Solids. 2020;137:103868

130. Norman TL, Yeni YN, Brown CU, Wang Z. Influence of micro damage on fracture toughness of the human femur and tibia. Bone. 1998;23:303-6.

131. Yeni YN, Norman TL. Fracture toughness of human femoral neck: Effects of microstructure, composition and age. Bone. 2000;26:499-504.

132. Rajapakse CS, Thomsen JS, Espinoza Ortiz JS, Wimalawansa SJ, Ebbesen EN, Mosekilde L, Gunaratne GH. An expression relating breaking stress and density of trabecular bone. J Biomech. 2004;37:1241-9.

133. Liebschner MA, Müller R, Wimalawansa SJ, Rajapakse CS, Gunaratne GH. Testing two predictions for fracture load using computer models of trabecular bone. Biophys J. 2005;89:759-67.

134. Hernandez CJ, Keaveny TM. A biomechanical perspective on bone quality. Bone. 2006;39:1173-81.

135. Carretta R, Stussi E, Muller R, Lorenzetti S. Within subject heterogeneity in tissue-level post-yield mechanical and material properties in human trabecular bone. J Mech Behav Biomed Mater. 2013;24:64-73.

136. Nawathe S, Yang H, Fields AJ, Bouxsein ML, Keaveny TM. Theoretical effects of fully ductile versus fully brittle behaviors of bone tissue on the strength of the human proximal femur and vertebral body. J Biomech. 2015;48:1264-9.

137. Sadoughi S. Micromechanics of human bone: Role of architecture and tissue material properties. Dissertation, UC Berkeley; 2019. https://escholarship.org/uc/item/2r77t0ww.

138. Neustadter DM, Drushel RF, Crago PE, Adams BW, Chiel HJ. A kinematic model of swallowing in Aplysia californica based on radula/odontophore kinematics and in vivo magnetic resonance images. J Exp Biol. 2002;205:3177-206.

139. Montroni D, Zhang X, Leonard J, Kaya M, Amemiya C, Falini G, Rolandi M. Structural characterization of the buccal mass of Ariolimax californicus (Gastropoda; Stylommatophora). PLoS One. 2019;14:e0212249.

140. Kehl CE, Wu J, Lu S, Neustadter DM, Drushel RF, Smoldt RK, Chiel HJ. Soft-surface grasping: Radular opening in Alysia californica. J Exp Biol. 2019;222:jeb191254.

141. Andersen SO, Peter MG, Roepstorff P. Cuticular sclerotization in insects. Comp Biochem Physiol. 1996;113B:689e705.

142. Vincent JFV, Wegst UG. Design and mechanical properties of insect cuticle. Arthropod Struct Dev. 2004;33:187e199.

143. Schöberl T, Jäger IL. Wet or dry - hardness, stiffness and wear resistance of biological materials on the micron scale. Adv Eng Mater. 2006;8:1164e1169.

144. Vincent JFV. If it's tanned it must be dry: A critique. J Adhes. 2009;85:755-69.

145. Klocke D, Schmitz H. Water as a major modulator of the mechanical properties of insect cuticle. Acta Biomater. 2011;7:2935-42.

146. Werth AJ, Harriss RW, Rosario MV, George JC, Sformo TL. Hydration affects the physical and mechanical properties of baleen tissue. Royal Soc Open Sci. 2016;3:160591.

147. Aberle B, Jemmali R, Dirks J-H. Effect of sample treatment on biomechanical properties of insect cuticle. Arthropod Struct Dev. 2017;46:138-46.

148. Huang W, Zaheri A, Yang W, Kisailus D, Ritchie RO, Espinosa H, McKittrick J. How water can affect keratin: hydration-driven recovery of bighorn sheep (Ovis canadensis). Horns. Adv Funct Mater. 2019;29:1901077.

149. Morris TE, Hickman CS. A method for artificially protruding gastropod radulae and a new model of radula function. Veliger. 1981;24:85-9.

150. Nassif N, Pinna N, Gehrke N, Antonietti M, Jager C, Colfen H. Amorphous layer around aragonite platelets in nacre. PNAS. 2005;102:12653-5.

151. Espinosa HD, Rim JE, Barthelat F, Buehler MJ. Merger of structure and material in nacre and bone - perspectives on de novo biomimetic materials. Progr Mater Sci. 2009;54:1059-110.

152. Heinemann F, Launspach M, Gries K, Fritz M. Gastropod nacre: structure, properties and growth - biological, chemical and physical basics. Biophys Chem. 2011;153:126-53.

153. Miserez A, Weaver JC, Pedersen PB, Schneeberk T, Hanlon RT, Kisailus D, Birkedal H. Microstructural and biochemical characterization of the nanoporous sucker rings from Dosidicus gigas. Adv Mater. 2009;21:401-6.

154. Hiew SH, Miserez A. Squid sucker ring teeth: multiscale structure-property relationships, sequencing, and protein engineering of a thermoplastic biopolymer. ACS Biomater Sci Eng. 2017;3(5):680-93.

155. Boßelmann F, Romano P, Fabritius H, Raabe D, Epple M. The composition of the exoskeleton of two crustacea: the American lobster Homarus americanus and the edible crab Cancer pagurus. Thermochim Acta. 2007;463:65-8.

156. Gorb SN, Beutel RG, Gorb EV, Jiao Y, Kastner V, Niederegger S, Popov VL, Scherge M, Schwarz U, Vötsch W. Structural design and biomechanics of frictionbased releasable attachment devices in insects. Integr Comp Biol. 2002;42:1127-39.

157. Peisker H, Michels J, Gorb SN. Evidence for a material gradient in the adhesive tarsal setae of the ladybird beetle Coccinella septempunctata. Nat Comm. 2013;4:1661.

158. Miserez A, Li Y, Waite JH, Zok F. Jumbo squid beaks: Inspiration for design of robust organic composites. Acta Biomater. 2007;3:139-49.

159. Miserez A, Schneberk T, Sun C, Zok FW, Waite JH. The transition from stiff to compliant materials in squid beaks. Science. 2008;319:1816-9.

160. Tan YP, Hoon S, Guerette PA, Wei W, Ghadban A, Hao C, Miserez A, Waite JH. Infiltration of chitin by protein coacervates defines the squid beak mechanical gradient. Nat Chem Biol. 2015;11:488-95.

161. Lin CP, Douglas WH, Erlandsen SL. Scanning electron microscopy of type I collagen at the dentin-enamel junction of human teeth. J Histochem Cytochem. 1993;41:381-8.

162. Marshall GW, Balooch M, Gallagher RR, Gansky SA, Marshall SJ. Mechanical properties of the dentinoenamel junction: AFM studies of nanohardness, elastic modulus, and fracture. J Biomed Mater Res. 2001;54:87-95.

Page $22 / 30$ 
163. Imbeni V, Kruzic JJ, Marshall GW, Marshall SJ, Ritchie RO. The dentin-enamel junction and the fracture of human teeth. Nat Mater. 2005;4:229-32.

164. Benjamin M, Toumi H, Ralphs JR, Bydder G, Best TM, Milz S. Where tendons and ligaments meet bone: Attachment sites ('entheses') in relation to exercise and/or mechanical load. J Anat. 2006;208:471-90.

165. Chan YL, Ngan AHW, King NM. Nano-scale structure and mechanical properties of the human dentine-enamel junction. J Mech Behav Biomed Mater. 2011;4:785-95.

166. Lu HH, Thomopoulos S. Functional attachment of soft tissues to bone: Development, healing, and tissue engineering. Annu Rev Biomed Eng. 2013;15:201-26.

167. Tertuliano OA, Greer JR. The nanocomposite nature of bone drives its strength and damage resistance. Nat Mater. 2016;15:1195-202.

168. Ukmar-Godec T. Mineralization of goethite in limpet radular teeth. In: Faivre D, editor. Iron oxides: From nature to applications. Weinheim: Wiley-VCH; 2016. pp. 207-24.

169. Evans LA, Macey DJ, Webb J. Characterization and structural organization of the organic matrix of radula teeth of the chiton Acanthopleura hirtosa. Philos Trans R Soc Lond B. 1990;329:87-96.

170. Wealthall RJ, Brooker LR, Macey DJ, Griffin BJ. Fine structure of the mineralized teeth of the chiton Acanthopleura echinata (Mollusca: Polyplacophora). J Morphol. 2005;265:165-75.

171. van der Wal P, Videler JJ, Havinga P, Pel R. Architecture and chemical composition of the magnetite-bearing layer in the radula teeth of Chiton olivaceus (Polyplacophora). In: Crick RE, editor. Origin, evolution, and modern aspects of biomineralization in plants and animals. Boston: Springer; 1989.

172. Wang C, Li QY, Wang SN, Qu SX, Wang XX. Microstructure and self-sharpening of the magnetite cap in chiton tooth. Mater Sci Eng C. 2014;37:1-8.

173. Golding RE, Ponder WF, Byrne M. Three-dimensional reconstruction of the odontophoral cartilages of Caenogastropoda (Mollusca: Gastropoda) using micro-CT: Morphology and phylogenetic significance. J Morphol. 2009;270:558-87.

174. Scheel C, Gorb SN, Glaubrecht M, Krings W. Not just scratching the surface: distinct radular motion patterns in Mollusca. Biol Open. $2020 ; 9:$ bio055699.

175. Zaslansky P, Shahar R, Friesem A, Weiner S. Relations between shape, materials properties, and function in biological materials using laser speckle interferometry: In situ tooth deformation. Adv Funct Mater. 2006;16:1925-36.

176. Michels J, Gorb SN. Mandibular gnathobases of marine planktonic copepods - feeding tools with complex micro- and nanoscale composite architectures. Beilstein J Nanotechnol. 2015;6:674-85.

177. Michels J, Gorb SN. Mandibular gnathobases of marine planktonic copepods - structural and mechanical challenges for diatom frustules. In: Hamm C, editor. Evolution of lightweight structures; 2015. p. 59-73.

178. Michels J, Vogt J, Simon P, Gorb SN. New insights into the complex architecture of siliceous copepod teeth. Zoology. 2015;118:141-6.

179. van Belle RA. De Europese Keverslakken. In: Goud J, van Belle RA, editors. Keverslakken. Vita Marina Zeebiologische Dokumentatie: Zeebiologie, Zeeaquariologie, Malacologie. Den Haag: Stichting Biologia Maritima; 1988. p. 1983.. : ; -. p. 9-128.

180. Mulisch M, Welsch U. Romeis Mikroskopische Technik. 18th ed. Heidelberg: Spektrum Akademischer Verlag; 2010.

181. Oliver WC, Pharr GM. An improved technique for determining hardness and elastic modulus using load and displacement sensing indentation experiments. J Mater Res. 1992;7:1564-83.

\section{Figures}

\section{Figure 1}

a. SEM image of one representative radula of Lepidochitona cinerea, working zone (Wz), taken from [174]. b, c, e, f. SEM image and EDX mapping from the embedded, native radula (working zone) from specimen number 1. c. Oxygen (0) distribution. e. Iron (Fe) distribution. f. Calcium (Ca) distribution. b. Red triangles represent the areas of nanoindentation for lateral tooth II (basis, stylus, cusp). d. Habitus from one representative specimen, taken from [174]. g. Light microscopy image of one native radula, working zone. Central teeth, lateral teeth I, marginal teeth are almost translucent, but slightly yellowish. The cusps of the lateral teeth II are clearly visible due to the high proportions of Fe. h. Light microscopy image of one treated radula, working zone. Central teeth, lateral teeth I, marginal teeth are more translucent. Scale bars: $\mathrm{a}-\mathrm{c}, \mathrm{e}-\mathrm{h}=100 \mu \mathrm{m}, \mathrm{d}=5 \mathrm{~mm}, \mathrm{E}=50 \mu \mathrm{m}$. Ct, central tooth; Lt I, lateral tooth I; Lt II, lateral tooth II; Mt, marginal tooth.

\section{Figure 2}

Embedded and polished samples, images obtained by light microscopy, and corresponding EDX spectra (the circles indicate the area of EDX analysis: basis, stylus, cusp). a. Lateral teeth II, working zone of the native radula from specimen number 2. b. Lateral teeth II, working zone of the treated radula from specimen number 1. c. EDX spectrum of the native stylus. d. EDX spectrum of the treated basis. e. EDX spectrum of the native cusp. f. EDX spectrum of the treated cusp. Scale bars: $a-b=100 \mu \mathrm{m}$. 


\section{Figure 3}

EDX and nanoindentation data obtained from native radulae $(n=3)$. a. Light microscopy image of one radula, tooth rows are numbered, and the zones (radular sack zone, mineralization zone, working zone) are defined. b. Changes in Young's modulus, GPa, during ontogeny for each tooth type and tooth part (Cu, cusp; St, stylus, Ba, basis). c. Changes in and Fe and Ca proportions (\%) during ontogeny for each tooth type and tooth part. Dots show values measured and solid lines show trend lines based on the individual measurements. Scale bar: A $=250 \mu \mathrm{m}$.

\section{Figure 4}

EDX and nanoindentation data obtained from treated radulae $(n=3)$. a. Light microscopy images of one radula, tooth rows are numbered, and the zones (radular sack, mineralization zone, working zone) are defined. b. Changes in Young's modulus, GPa, during ontogeny for each tooth type and tooth part (Cu, cusp; St, stylus, Ba, basis). c. Changes in and Fe and Ca proportions (\%) during ontogeny for each tooth type and tooth part. Dots show values measured and solid lines show trend lines based on the individual measurements. Scale bar: $A=200 \mu \mathrm{m}$. 


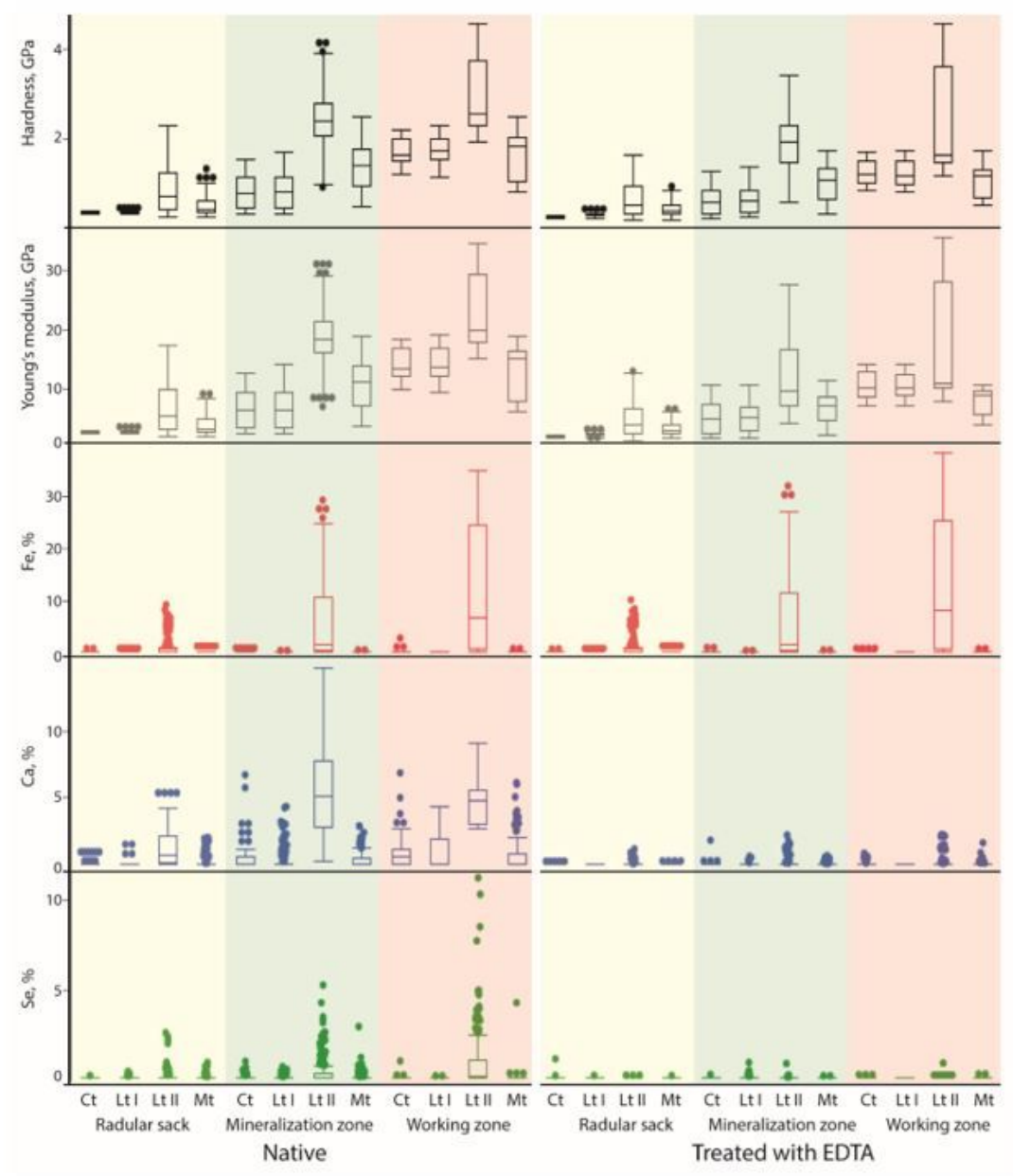

Figure 5

For each tooth type (Ct, central tooth; Lt I, lateral tooth I; Lt II, lateral tooth II; Mt, marginal tooth) and each zone: Hardness, GPa, Young's moduli, GPa, and Fe, $\mathrm{Ca}$, and slightly distributed elements (Se) as proportion, \%. Left side: native radulae, right side: treated radulae. 
Figure 6

a-b. Broken teeth (Ct, central tooth; Lt I, lateral tooth I; Lt II, lateral tooth II; Mt, marginal tooth) of a. one dry, native radula and b. one wet, treated radula. C. Breaking force, $\mathrm{mN}$, for each radular zone, tooth type, and condition (native dry, native wet, treated dry, treated wet) with quantity $(n)$ of broken teeth. Scale bars: $a-b=200 \mu m$. D, dry; W, wet. 

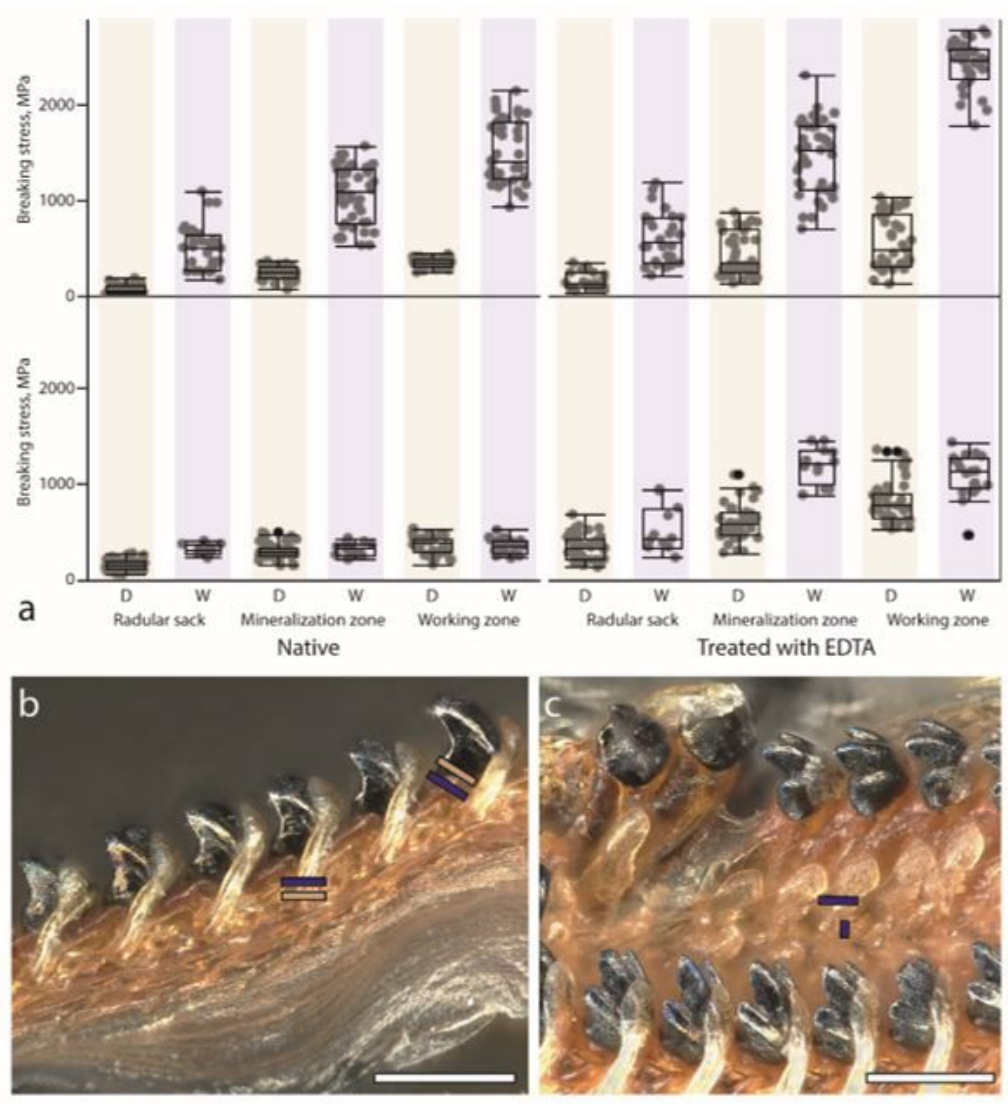

\section{Figure 7}

a. Calculated breaking stress, MPa, for each radular zone and condition (native dry, native wet, treated dry, treated wet) with quantity ( $n$ ) of broken teeth that could be used for calculation. b-c. Region of structural failure under dry (brown) or wet condition (blue). Scale bars: $b-c=100 \mu m$. D, dry; W, wet. 


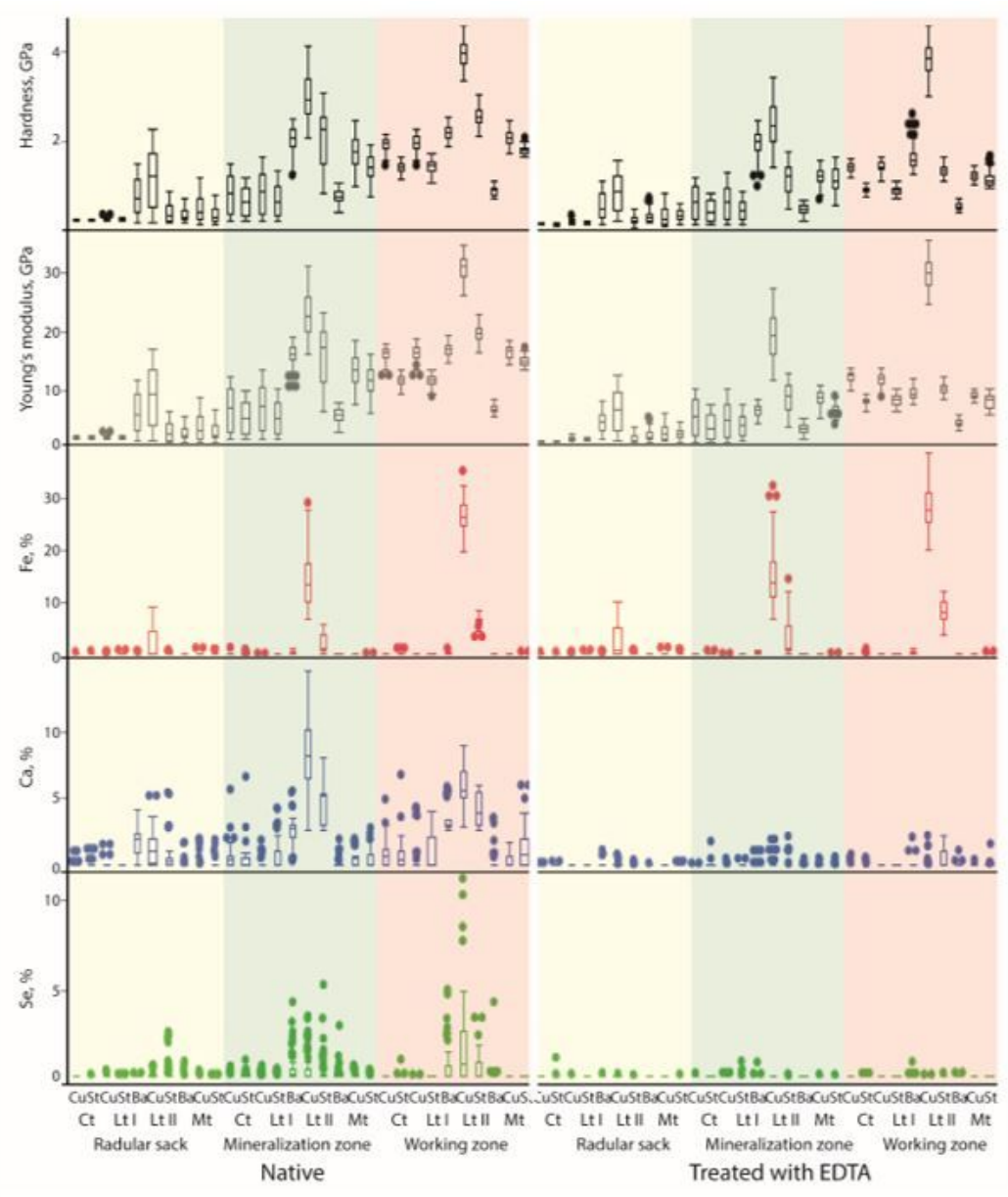

Figure 8

For each tooth type (Ct, central tooth; Lt I, lateral tooth I; Lt II, lateral tooth II; Mt, marginal tooth), part (Cu, cusp; St, stylus, Ba, basis), and each zone: Hardness, $\mathrm{GPa}$, Young's moduli, $\mathrm{GPa}$, and $\mathrm{Fe}, \mathrm{Ca}$, and slightly distributed elements (Se) as proportion, \%. Left side: native radulae, right side: treated radulae. 


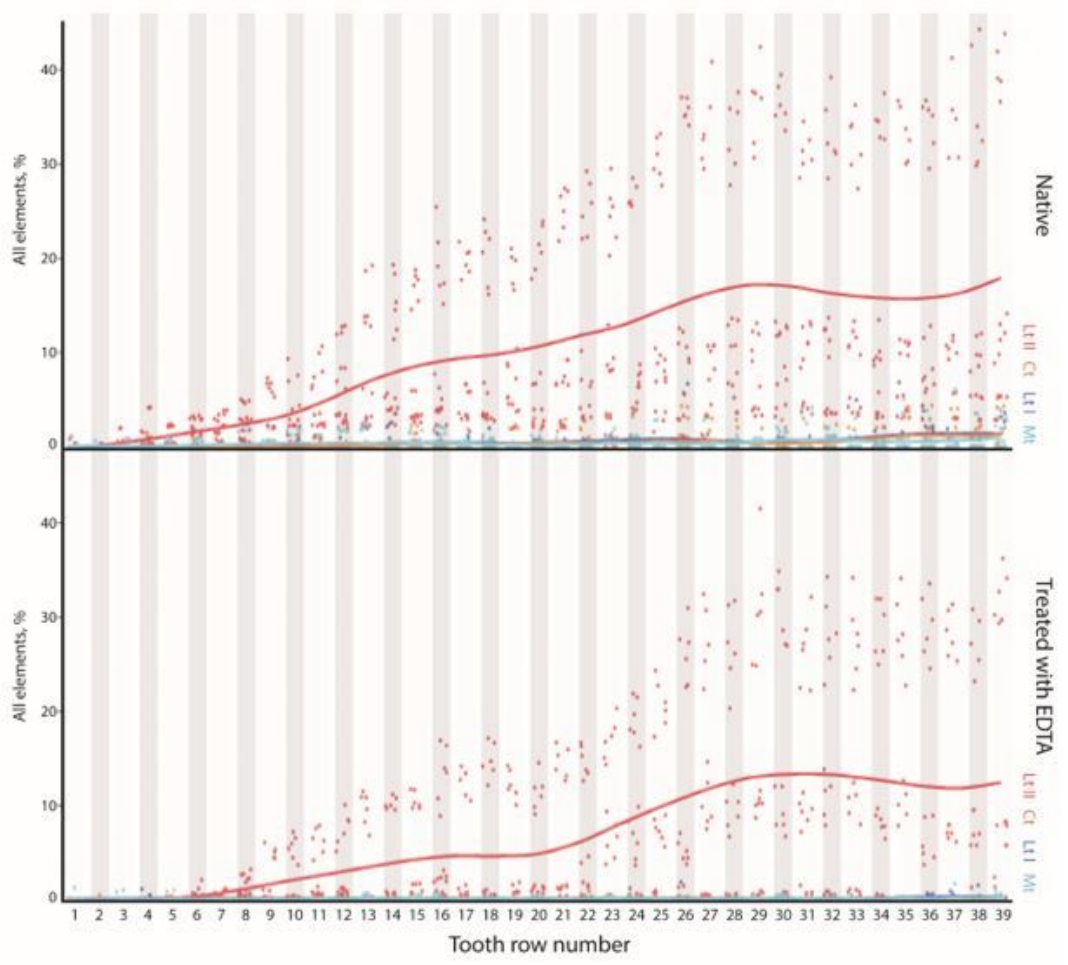

Figure 9

Changes in proportion of all elements, \%, during ontogeny for each tooth type (Ct, central tooth; Lt I, lateral tooth I; Lt II, lateral tooth II; Mt, marginal tooth); values and trend lines for native (above) and treated (below) radulae.

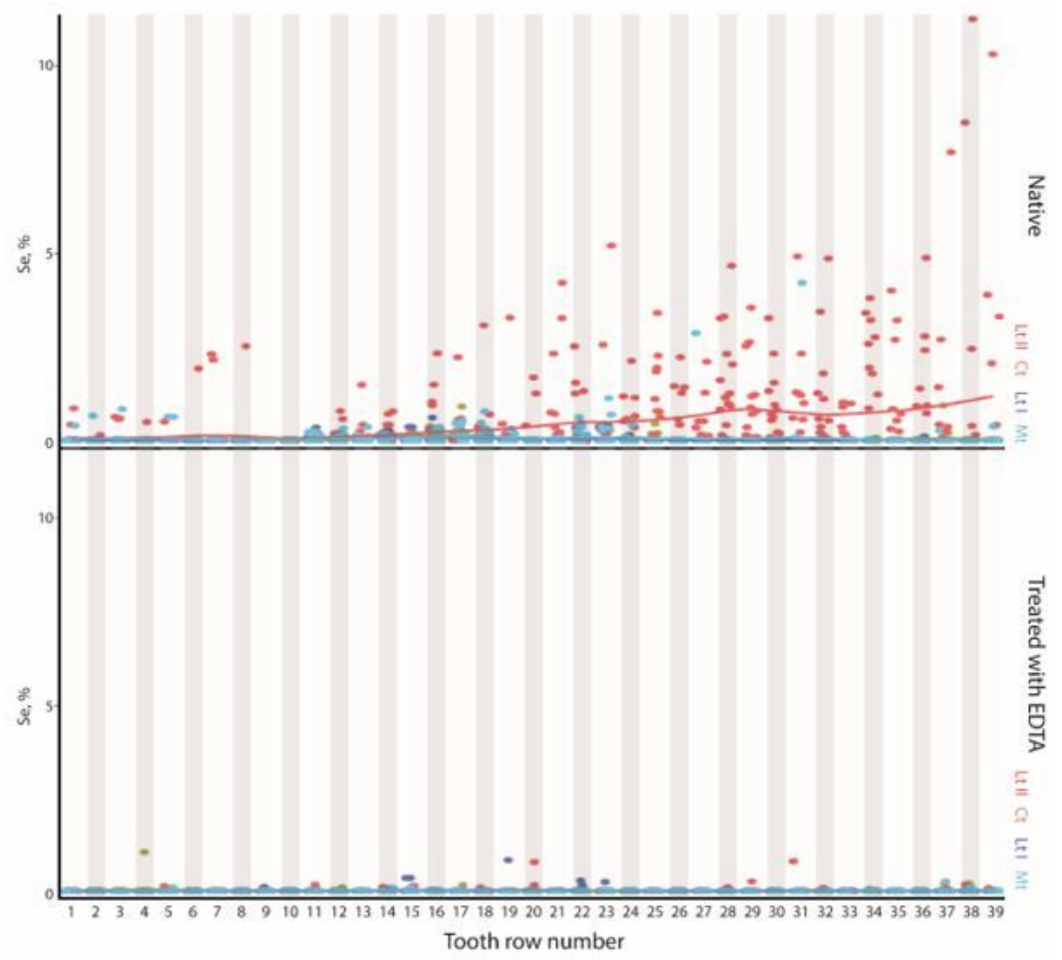

Figure 10

Changes in proportion of slightly distributed elements (Se), \%, during ontogeny for each tooth type (Ct, central tooth; Lt I, lateral tooth I; Lt II, lateral tooth II; Mt, marginal tooth); values and trend lines for native (above) and treated (below) radulae. 


\section{Supplementary Files}

This is a list of supplementary files associated with this preprint. Click to download.

- Supplement5final.pdf 